\title{
TARGET SELECTION BY SURGICALLY MISDIRECTED OPTIC FIBERS IN THE TECTUM OF GOLDFISH ${ }^{1}$
}

\author{
RONALD L. MEYER \\ Developmental Biology Center and Department of Developmental and Cell Biology, University of California, Irvine, \\ Irvine, California 92717
}

Received July 16, 1982; Revised July 25, 1983; Accepted August 2, 1983

\begin{abstract}
This study tested the capacity of regenerating optic fibers to read tectal markers and thereby grow to their appropriate tectal loci when initial position, optic pathway, and interfiber interactions are eliminated as useful cues. 'T'he stability of these markers with long-term optic denervation of the tectum was also examined. In adult goldfish optic fibers innervating lateroposterior optic tectum were dissected free of tectum and inserted into the medial anterior region of the opposite "host" tectum. Normally, fibers at this position either innervate medial anterior tectum or follow the medial division of the optic pathway into medioposterior tectum. Host tectum was denervated of all other optic fibers by enucleating its contralateral eye either at the time of the deflection or at various times up to 18 months prior to deflection. The regeneration of these deflected fibers into host tectum was examined by autoradiography and electrophysiology at 1 to 11 months later. At the insertion site deflected fibers split into two groups of roughly equal size. One group directly entered the optic layers of medial tectum and grew posterolaterally across the medial half of tectum into the lateral half. The second group followed an almost direct path to the lateral tectum, sometimes traversing through the deep cell layers of tectum in which optic fibers are not uusually found. These fibers subsequently entered the optic layers at the lateral edge of tectum and grew posteriorly. This second path was not seen in controls in which optic fibers from medioposterior tectum were similarly deflected. Instead growth was almost entirely posteriorly directed. On the average by 1.5 months deflected lateroposterior fibers were preferentially distributed in the lateral half of the tectum. Densitometric measurements indicated nearly a 4-fold difference in lateroposterior compared with medial posterior labeling. By contrast, controls in which medial posterior fibers were deflected had 4 times more grains medially than laterally. There was also a posterior over anterior preference, but this was weak. There was no suggestion that long periods of optic denervation prior to deflection or long postoperative periods after deflection of lateroposterior fibers diminished the lateral over medial preference. These findings support the idea that stable tectal markers exist which are differentially read by medial and lateral optic fibers. However, in no case was the innervation by deflected fibers as selective as in the normal projection. It is argued that the weak selectivity particularly for the anterior-posterior axis is not due to an absence of markers but rather to an absence of interfiber interactions and to a tendency of deflected fibers to terminate along their growth path.
\end{abstract}

For the problem of how nerve fibers form selective connections in development, several long-standing issues continue to be raised. Three in particular have been the focus of a number of seemingly conflicting models. The first issue is the extent to which fibers have and use intrinsic position-dependent markers to direct their growth as in the chemoaffinity hypothesis (Sperry, 1963; Hunt and Jacobson, 1974; Meyer and Sperry, 1976;

${ }^{1}$ This work was supported by Public Health Service Grant NS 15381.
Fraser and Hunt, 1970). The second is whether time and positional factors together with mechanical guidance structures, i.e., factors extrinsic to retinal and tectal cells, are responsible for order (Horder and Martin, 1978; Singer et al., 1979; Bunt, 1982). The third is the possible contribution of interfiber interactions which might generate interfiber ordering independent of tectal markers (Gaze and Keating, 1972; Jacobson and Levine, 1975; Mcyer, 1978a; Cook, 1979; Sharma and Tung, 1979). These might act either indirectly such as by competition 
for synaptic space (Prestige and Willshaw, 1975) or directly such as by contact affinities between fibers (Meyer and Sperry, 1976; Meyer, 1978a; Fraser and Hunt, 1980). Though these questions have been frequently addressed in research using regenerating retinotectal fibers, agreement on the relative merits of these ideas remains elusive. One reason for the uncertainty has been the difficulty of absolutely excluding any two of the above categories of models in any experiment. Thus, many studies lend themselves to several alternative interpretations. In the particular case of studies aimed at examining the possible role of retinal and tectal markers (e.g., chemoaffinity), in general it has not been possible entirely to eliminate or accurately assess the contribution from time-position-mechanical guidance factors and interfiber interactions. Consequently, the nature and magnitude of the role of marker-dependent growth still needs clarification. For example, in the study by Attardi and Sperry (1963), selective reinnervation of the tectum was observed following combined nerve crush and partial retinal ablations. The original interpretation was that fibers exhibit chemoaffinity preferences for their appropriate tectal loci. Subsequently, this result was interpreted in terms of mechanical order within the optic nerve and tract (Horder and Martin, 1978; Bunt, 1982). Later studies have reported expanded projections from partial retinas (Schmidt et al., 1978) or compression of an intact retina onto a half-tectum (Gaze and Sharma, 1979; Meyer, 1977) and have prompted explanations invoking interfiber interactions (Gaze and Keating, 1972; Prestige and Willshaw, 1975). Other important experiments indicative of positional labels are those in which a piece of tectum is rotated or translocated. The original finding was that fibers grow to their orginal tectal loci (Sharma and Gaze, 1971; Yoon, 1973). Later a substantial number of exceptions were found in which fibers ignored the origin of the transplant, (Jacohson and I evine, 1975; Rho and Hunt, 1980). These again have been interpreted as interfiber interactions or effects of timing and position or mechanical guidance. Other work suggestive of tectal labels was from pathway analysis following simple nerve crush. Many optic fibers were found to travel abnormal routes and yet form a retinotopic projection (Horder, 1974; Udin, 1978; Meyer, 1980; Fujisawa, 1981). However, this has been interpreted as interfiber interactions with minimum polarity cues given by tectum or adjacent structures (Hope et al., 1976). It might also be argued that the majority of regenerating fibers arrived at their appropriate tectal loci by growing along the correct pathway and the remaining fibers which traveled anonalous routes simply located their correct retinal neighbor by interfiber interactions rather than by reading tectal labels. The question of stability of these putative retinal and tectal markers has also been raised (Mayer and Sperry, 1976; Schmidt, 1978). It has been claimed that if the tectum is denervated of optic fibers for many months, its positional markers disappear; or if an expanded projection from a half-retina is allowed to exist for many months, the tectal markers change to conform to the expanded projection (Schmidt, 1978). It is also commonly recognized that degeneration debris is a potential complication in most regeneration experiments, but rarely has it been possible to control for its effects.

The present study is an effort to further clarify the role and determine the stability of putative retinal and tectal labels in the formation of topography. For the present purposes these labels are meant in an operational sense, i.e., as position-dependent properties of retina and tectum that somehow produce selective growth of optic fibers. No assumptions are made as to underlying mechanisms and chemical nature. The experimental question asked is where will a selected fraction of optic fibers grow if they are directly inserted into an incorrect tectal position and pathway when no other optic fibers are present in the tectum. In this case initial position and pathway cues should work against marker-mediated growth. Also there is no opportunity for cuing from fibers from other retinal regions; i.e., differential timing or interfiber interactions from these other fibers can be excluded. Selective interfiber interactions are particularly important to rule out since selective innervation could be interpreted in these terms even if misrouted fibers find their appropriate tectal site. As mentioned above it is possible that misrouted fibers cue in on the homotopic retinal fibers which were not misrouted and arrived at their correct tectal site by following nonspecific pathway cues. If appropriate innervation were to form under the proposed conditions, marker-mediated growth would be clearly implicated. On the other hand inappropriate innervation would suggest that markers cannot override all initial errors of position and pathway, and their existence or stability might be questioned. Since the results, in fact, did point to the existence of marker-mediated growth, it was further asked if the selective innervation pattern was altered by long postoperative survival or by a long period of prior optic denervation of tectum. A decrease in selective innervation with time would be consistent with the notion that tectal labels are labile, i.e., require optic innervation for their maintenance. Undiminished selectivity would demonstrate stability of these labels and their independence of optic innervation for maintenance. Varying the period of prior denervation would also test for the possible contribution of degeneration debris which is known to be resorbed with time.

The experiment used regenerating optic fibers in mature goldfish because this system is amenable to a surgical technique by which a relatively small number of selected optic fibers can be inserted into specific tectal regions (Meyer, 1978a; 1979). Specifically, fibers that normally innervate posterolateral tectum were deflected into the medial anterior edge of the opposite host tectum. This insertion site is the maximal distance from the appropriate tectal quadrant and is in the far medial division of the optic tract which supplies medial rather than lateral tectum. The host tectum was denervated of other optic fibers by enucleation of its contralateral eye to eliminate interactions with fibers from other retinal regions. The stability of the putative tectal labels as well as the possible effect of degeneration debris was tested by varying the period of enucleation prior to deflection 
and the period after deflection. Autoradiographic and electrophysiological methods were used to trace the deflected fibers.

\section{Materials and Methods}

Animals. Juvenile common goldfish, 5 to $7 \mathrm{~cm}$ in body length, were maintained in standard aquaria. Illumination was of low intensity and diurnal, with $12 \mathrm{hr}$ light, and $12 \mathrm{hr}$ dark (Table I).

Surgery. The surgical methods were similar to those described previously (Meyer, 1978a; 1979). Under tricaine methanesulfonate anesthesia, a large flap was removed over the tectum. A curved glass pipette serving as a combined aspirator and retractor was used to expose the lateral half of the tectum. With a fine needle, a long strip of the lateral edge of the right tectum was freed from surrounding tectum except at its anterior end. This strip was essentially the lateral and lateroposterior tectal margin plus 300 to $500 \mu \mathrm{m}$ of adjacent tectum. It included those fibers which arrive through the ventrolateral brachia of the optic tract which supply the lateroposterior tectal quadrant. The integrity of the anterior end of the optic fibers was preserved in the tectal strip; i.e., their connection with left retina was intact. For the controls fibers were taken from the medial edge of the tectum as in a previous study (Meyer, 1978a). These fibers supply medial posterior tectum. In both cases the posterior end of the strip was then lifted across the midline and inserted into a $300-$ to $500-\mu \mathrm{m}$ incision at the anteromedial edge of left tectum. The cranial flap was replaced. The right eye was enucleated by cutting away the muscles, nerves, and other attachments with iridectomy scissors and removing the eye. In some animals only enucleation was performed. Fish recovered normal swimming movements in a few minutes without signs of motor dysfunction.

Autoradiography. The vitreous of the left eye was injected with 25 to $50 \mu \mathrm{Ci}$ of tritiated proline in $1 \mu \mathrm{l}$ of $\mathrm{H}_{2} \mathrm{O}$. This was delivered through a 33-gauge needle which was inserted into the limbus and advanced until the tip was behind the center of the lens. After 12 to $24 \mathrm{hr}$ the brain was fixed by immersion in a mixture of formalin, acetic acid, and alcohol. Serial paraffin sections, 20 to 30 $\mu \mathrm{m}$ thick, were taken in frontal orientation from the chiasm to the posterior end of the tectum. They were subsequently exposed to NTB-2 emulsion for 1 week using standard procedures (Cowan et al., 1972). A light cresyl violet stain followed.

Electrophysiology. An eye-in-water recording apparatus instead of the usual eye-in-air method was used

TABLE I

Table of animals

\begin{tabular}{|c|c|c|c|c|c|}
\hline No. & Name & $\begin{array}{l}\text { Type of } \\
\text { Surgery }\end{array}$ & $\begin{array}{l}\text { Days after } \\
\text { Deflection } \\
\text { at Time of } \\
\text { Labeling }\end{array}$ & $\begin{array}{c}\text { Days of } \\
\text { Enucleation } \\
\text { Prior to } \\
\text { Deflection }\end{array}$ & Procedure \\
\hline 1 & LB 1 & Lateral deflection & 24 & 0 & Autoradiography \\
\hline 2 & LB 12 & Lateral deflection & 30 & 56 & Autoradiography \\
\hline 3 & LB 13 & Lateral deflection & 30 & 56 & Autoradiography \\
\hline 4 & LB 14 & Lateral deflection & 30 & 56 & Autoradiography \\
\hline 5 & LB 3 & Lateral deflection & 49 & 28 & Autoradiography \\
\hline 6 & LB 17 & Lateral deflection & 51 & 56 & Autoradiography \\
\hline 7 & LB 2 & Lateral deflection & 77 & 0 & Autoradiography \\
\hline 8 & LB 6 & Lateral deflection & 90 & 24 & Autoradiography \\
\hline 9 & LB 7 & Lateral deflection & 90 & 24 & Autoradiography \\
\hline 10 & LB 8 & Lateral deflection & 90 & 533 & Autoradiography \\
\hline 11 & LB 4 & Lateral deflection & 96 & 0 & Autoradiography \\
\hline 12 & LB 5 & Lateral deflection & 96 & 0 & Autoradiography \\
\hline 13 & LB 10 & Lateral deflection & 104 & 533 & Autoradiography \\
\hline 14 & LB 9 & Lateral deflection & 109 & 0 & Autoradiography \\
\hline 15 & LB 11 & Lateral deflection & 115 & 533 & Autoradiography \\
\hline 16 & I.B 15 & Lateral deflection & 167 & 28 & $\begin{array}{c}\text { Autoradiography and } \\
\text { electrophysiology }\end{array}$ \\
\hline 17 & LB 18 & Lateral deflection & 329 & 28 & $\begin{array}{l}\text { Autoradiography and } \\
\text { electrophysiology }\end{array}$ \\
\hline 18 & LB 19 & Lateral deflection & 330 & 28 & $\begin{array}{l}\text { Autoradiography and } \\
\text { electrophysiology }\end{array}$ \\
\hline 19 & LB 20 & Lateral deflection & 330 & 28 & Autoradiography \\
\hline 20 & MB 7 & Medial deflection & 31 & 14 & Autoradiography \\
\hline 21 & MB 8 & Medial deflection & 52 & 14 & Autoradiography \\
\hline 22 & MB N1 & Medial deflection & 96 & 0 & Autoradiography \\
\hline 23 & MB N2 & Medial deflection & 96 & 0 & Autoradiography \\
\hline 24 & MB 20 & Medial deflection & 747 & 14 & Autoradiography \\
\hline 25 & EN 1 & No deflection & & 33 & Autoradiography \\
\hline 26 & EN 2 & No deflection & & 336 & Autoradiography \\
\hline 27 & EN 3 & No deflection & & 336 & Autoradiography \\
\hline 28 & EN 4 & No deflection & & 913 & Autoradiography \\
\hline 29 & EN 5 & No deflection & & 913 & Autoradiography \\
\hline
\end{tabular}


because it permits mapping the extreme periphery of the visual field. Recordings were from units or multiple units and were made with platinum-tipped electrodes insulated with glass. Fish were immobilized with curare. A detailed description has been given previously (Meyer, 1977).

Photomicroscopy. Each of the photomontages of host tectum consisted of four photomicrographs taken as follows. The most anterior photomicrograph was of the insertion site. The remaining three divided posterior tectum into four equal parts as determined by counting the number of sections between the first photomicrograph and the most posterior section containing host tectum. For the montages all bright-field photomicrographs were taken on a single roll of film. Dark-field photomicrographs were taken on a second roll. Photographic printing was controlled for uniformity of magnification, contrast, and exposure. Variability in the appearance of tecta between fish is due to variability in cresyl violet staining.

Microdensitometry. In order to be sensitive to the detection of fibers in foreign tectal regions, the exposure was such as to give relatively high grain densities in the areas of maximal innervation. Consequently, the autoradiograms were unfavorable for grain counting which becomes difficult and inaccurate at high densities (Goldstein and Williams, 1971). Instead, gross absorbance (-log transmittance) which is linearly related to exposure over a larger density range (Goldstein and Williams, 1971) was used. Since exposure time was constant, then in practice absorbance was a linear function of amount of radioactivity. The system was a standard transmitted light microscope having stabilized quartz iodide light source, an eyepiece containing a $1-\mathrm{mm}$ pinhole in its internal image plane, and a photomultiplier tube behind this eyepiece. The effective diameter of the measuring spot was $55 \mu \mathrm{m}$. The reference reading (incident illumination) was determined by reading a nonspecifically labeled brain region, such as cerebellum, on the same section. Regional density variations in the tissue itself were effectively eliminated by keeping the stain light and inserting a Kodak Wratten No. 47B filter in front of the photomultiplier.

For each reading the measuring spot was centered over the main optic layer, the combined stratum opticum (SO) and stratum fibrosum et griseum superficiale (SFGS) (Vanegas et al., 1974). The $55-\mu \mathrm{m}$ diameter of the spot was approximately the maximal thickness of this layer $(\mathrm{SO}+\mathrm{SFGS})$ in host tectum. Three such readings from immediately contiguous positions in this layer were averaged to give an integrated absorbance from a region which was roughly $55 \mu \mathrm{m}$ deep and $165 \mu \mathrm{m}$ wide. Sixteen of these $55-\times 165-\mu \mathrm{m}$ "strip measurements" were taken in host tectum and two in donor tectum. Four sections were selected for measurement. These were $0.12,0.36$, 0.6 , and 0.85 of the total number of tectal sections from anterior to posterior, respectively. Thus, they were equally spaced along the anteroposterior axis and as a whole shifted slightly anteriorly to compensate partly for the smaller size of the posterior tectal cross-section. In host tectum four strip measurements were taken from each of these sections. One was near the medial edge (centered approximately $150 \mu \mathrm{m}$ in from the extreme tectal edge), one was near the lateral edge (also centered approximately $150 \mu \mathrm{m}$ in), and two were equally spaced from the medial and lateral edges (one-third tectal circumference or 700 to $1000 \mu \mathrm{m}$ in from the medial or lateral edge). In effect these measurements approximated a nearly equally spaced $4 \times 4$ matrix of measurements of host tectum. In donor tectum one strip measurement each was taken of the 0.36 and 0.6 (anteroposterior) sections at one-third of the tectal circumference in from the medial edges in fish in which lateral fibers were deflected and one-third in from the lateral edge in fish in which medial fibers were deflected.

\section{Results}

To check whether enucleation was effective at denervating tectum on a long-term basis, i.e., whether enucleation produced ipsilateral growth of optic fibers, one eye was removed and no fibers were deflected in five fish. At 33 (one fish), 336 (two fish), and 913 (two fish) days later, the remaining eye was injected with tritiated proline. No label could be detected in denervated tectum.

All the remaining fish received both enucleation and deflection. The control deflection of medioposterior fibers (corresponding to inferior nasal retina) into medioanterior tectum will be briefly described first. A detailed qualitative account of both autoradiography and electrophysiology has been given previously (Meyer, 1978a). The large majority of deflected fibers grew posteriorly from the insertion site so that at all postoperative times the bulk of the label remained within the medial half of tectum. Some label also extended from medial tectum into lateral tectum in decremental fashion; i.e., within the lateral half it progressively decreased in the medial to lateral direction until little or no label was detectable at the lateral edge. There was also differential labeling along the anteroposterior dimension with heavier label in the posterior half. However, this difference was a modest one so that both anterior and posterior halves were well labeled. Lamination was approximately normal except near the insertion site (see below description for lateroposterior fibers). All the major optic layers could be identified in those tectal regions with heavy labeling. However, the main optic innervation layer, the stratum fibrosum et griseum superficiale, was always thinner than normal, and grain density was always discernibly decreased from normal as judged by comparison with label from undeflected fibers in donor tectum.

Densitometric measurements were made on five of these fish. Enucleation was either simultaneous with deflection or preceded it by 14 days. The survival time after deflection was $31,52,96$, or 747 days. The temporal parameters are summarized in Table II, which also includes the densitometric measurements for each of the five fish. The 16 densitometric measurements of host tectum are arranged as a $4 \times 4$ matrix such that the relative positions of the measurements are preserved. The top row represents the four measurements from the most anterior section with left to right corresponding to medial to lateral. Each successive row corresponded to the next posterior set of measurements with medial again 
at the left. One can think of this representation of the data as a tectal map with anterior at the top and medial at the left. It is immediately obvious that in all five fish the medial half of the rectum (two left columns) had a substantially higher integrated absorbance than did the lateral half (two right columns). Since integrated absorbance is linearly related to exposure and hence to amount of label when exposure time is constant and since the label was distributed in a slowly varying graded fashion across the tectum, then a rough index of the mediallateral difference can be taken as the ratio of the sum of medial measurements (two left columns) over the sum of the lateral measurements (two right columns) or M/ L. The value of $\mathrm{M} / \mathrm{L}$ ranged from 3.8 to 16 (Table II) with the highest value for the fish at 31 days postoperatively. A previous autoradiographic study of regenerating optic fibers in this system (Meyer, 1980) points to a number of differences between a 1 -month postoperative time and 2 months or more which must be considered. At 1 month not all fibers have yet reached their final position, but by 2 months most fibers are at or close to their final positions. At 1 month axoplasmic transport is markedly elevated as is labeling of fibers of passage. Label in the innervation layer is fasciculated in its density and pattern of distribution. For these reasons it may be inappropriate simply to pool the measurements from fish at 1 month or less with those from fish at 2 months

TABLE II

Densitometry medial deflection

Density readings are $\times 1000$.

\begin{tabular}{|c|c|c|c|c|c|c|c|c|}
\hline \multirow{3}{*}{$\begin{array}{c}\begin{array}{c}\text { Animal } \\
\text { Name } \\
\text { (Postoperative) }\end{array} \\
\text { MB } 7(31,14)^{b}\end{array}$} & \multicolumn{4}{|c|}{ Host Tectum } & \multirow[b]{2}{*}{$\begin{array}{c}\text { Donor } \\
\text { Tectum } \\
\text { (Midlateral) }^{a}\end{array}$} & \multicolumn{3}{|c|}{ Ratios } \\
\hline & \multicolumn{2}{|c|}{ Medial $^{a}$} & \multicolumn{2}{|c|}{ Lateral } & & $\begin{array}{l}\mathrm{M} / \mathrm{L} \\
\mathrm{M} / \mathrm{L} \mathrm{A} \\
\mathrm{M} / \mathrm{L} \mathrm{P}\end{array}$ & \multirow{2}{*}{$\begin{array}{l}\mathrm{P} / \mathrm{A} \\
\mathrm{P} / \mathrm{A} \mathrm{M} \\
\mathrm{P} / \mathrm{A} \mathrm{L}\end{array}$} & \multirow{2}{*}{$\begin{array}{l}\mathrm{H} / \mathrm{D} \\
1.2\end{array}$} \\
\hline & 114 & 57 & 7 & 9 & & 16 & & \\
\hline & 189 & 78 & 3 & 3 & 153 & 20 & 0.95 & \\
\hline & 149 & 78 & 4 & 6 & 161 & 13 & 1.5 & \\
\hline & 116 & 74 & 15 & 7 & & & & \\
\hline \multirow[t]{4}{*}{ MB $8(52,14)$} & 90 & 54 & 10 & 6 & & 8.8 & 1.2 & 0.31 \\
\hline & 76 & 64 & 3 & 4 & 329 & $1 \%$ & 1.1 & \\
\hline & 88 & 66 & 6 & 7 & 302 & 7 & 2.0 & \\
\hline & 97 & 72 & 12 & 21 & & & & \\
\hline \multirow[t]{4}{*}{ MBN $1(96,0)$} & 60 & 57 & 12 & 4 & & 4.1 & 1.2 & 0.39 \\
\hline & 76 & 99 & 32 & 4 & 250 & 5.6 & 1.1 & \\
\hline & 78 & 95 & 41 & 4 & 260 & 3.2 & 1.8 & \\
\hline & 59 & 76 & 44 & 7 & & & & \\
\hline \multirow[t]{4}{*}{ MBN $2(96,0)$} & 54 & 38 & 9 & 6 & & 6.4 & 0.99 & 0.63 \\
\hline & 67 & 38 & 6 & 0 & 106 & 9.4 & 0.90 & \\
\hline & 36 & 47 & 10 & 0 & 108 & 4.7 & 1.8 & \\
\hline & 38 & 57 & 25 & 3 & & & & \\
\hline \multirow[t]{4}{*}{ MB $20(747,14)$} & 15 & 13 & 0 & 0 & & 3.8 & 1.8 & 0.40 \\
\hline & 21 & 24 & 4 & 1 & 59 & 15 & 1.4 & \\
\hline & 21 & 27 & 16 & 3 & 81 & 2.5 & 8.2 & \\
\hline & 28 & 27 & 22 & 0 & & & & \\
\hline
\end{tabular}

${ }^{a}$ For the $4 \times 4$ measurements, the left column is from the medial tectum, the right column is lateral, the top row is anterior, and the bottom row is posterior. See the text for details.

${ }^{b}$ The first number is days after deflection at time of labeling. The second number is days of enucleation prior to deflection. or more. All the calculated averages reported below, therefore, will exclude fish at 1 month or less. The average $\mathrm{M} / \mathrm{L}$ is $5.8 \pm 2.3$ (standard deviation). $\mathrm{M} / \mathrm{L}$ was also separately calculated for the anterior half $(\mathrm{M} / \mathrm{L}-\mathrm{A})$ and posterior half $(\mathrm{M} / \mathrm{L}-\mathrm{P})$ of the tectum. Without exception M/L-A was larger than M/L-P for each fish. The average $\mathrm{M} / \mathrm{L}-\mathrm{A}$ was $10.5 \pm 4.0$ compared with an $\mathrm{M} / \mathrm{L}$ $\mathrm{P}$ of $4.4 \pm 2.0$.

A posterior/anterior ratio $(\mathrm{P} / \mathrm{A})$ can be calculated similarly to the method for $\mathrm{M} / \mathrm{L}$ as the sum of the first two rows of absorbance readings over the sum of the last two rows. $\mathrm{P} / \mathrm{A}$ ranged from 0.98 to 1.8 with an average (excluding the 31-day animal) of $1.3 \pm 0.35$, indicating that label was either evenly distributed across the anteroposterior axis or greater in the posterior half. P/A calculated for only the medial half (P/A-M) was similar with an average of $1.1 \pm 0.21$. By contrast $\mathrm{P} / \mathrm{A}$ for the lateral half $(\mathrm{P} / \mathrm{A}-\mathrm{L})$ was in all cases higher than $\mathrm{P} / \mathrm{A}$ and $\mathrm{P} / \mathrm{A}-\mathrm{M}$, ranging from 1.5 to 8.2 with an average of $3.4 \pm$ 3.2 .

Finally, the peak density of label in host tectum relative to presumably normal or donor tectal label (H/D) was determined by taking the highest single density reading in host tectum over the average of the twodensity readings in donor tectum. With the single exception of the 31 -day fish where $H / D=1.2$, reflecting increased transport, $H / D$ was much less than 1 , on the average of $0.43 \pm 0.14$.

All the average ratios are summarized in Table IV. Table IV also includes the normalized average densitometry readings for all the above fish except the 31-day animal. For this calculation the highest densitometry reading in host tectum for each fish was set at 100 , and the readings at the other tectal positions were normalized accordingly. The normalized reading for each tectal position from all fish was then averaged to give the $4 \times 4$ matrix in Table IV.

The results from deflection of lateroposterior fibers will now be described (Table III). At 24 or 30 days from deflection (four fish), label in regenerating deflected fibers was much heavier than normal and gave the appearance of being distributed along the shafts of fibers rather than concentrated at the terminal as is typical for early stages of regeneration (Grafstein and Murray, 1969; Meyer, 1980). In the donor side deflected fibers which could be seen as a dense band of grains could be traced from the lateral brachia of the optic tract of anterior tectum and across the surface of the anterior end of tectum. It then spanned the midline and invaded host tectum at its anteromedial edge where it was inserted (Fig. 1A). At the entry point into host tectum, fibers typically intruded as far as the main layers of tectum, the stratum griseum centrale et periventriculare (see Vanegas et al., 1974), into which optic fibers ordinarily do not grow. These cell layers will be referred to as the deep cell layers of tectum. This deep label was probably surgically produced. The depth to which fibers were inserted was not controlled, and this kind of label has been seen in previous deflection studies (Meyer, 1978a, 1979). In two cases a large neuroma-like ball of label could be seen within these deep layers.

In each animal the fibers followed two general paths 
TABLE III

Densitometry lateral deflection

Density readings are $\times 1000$.

\begin{tabular}{|c|c|c|c|c|c|c|c|c|}
\hline \multirow{2}{*}{$\begin{array}{c}\text { Animal } \\
\text { Name } \\
\text { (Postoperative) }\end{array}$} & \multicolumn{4}{|c|}{ Host Tectum } & \multirow[b]{2}{*}{$\begin{array}{c}\text { Donor } \\
\text { Tectum } \\
\text { (Midmedial) }\end{array}$} & \multicolumn{3}{|c|}{ Ratios } \\
\hline & \multicolumn{2}{|c|}{ Medial $^{a}$} & \multicolumn{2}{|c|}{ Lateral } & & $\begin{array}{l}\mathrm{L} / \mathrm{M} \\
\mathrm{L} / \mathrm{MA} \\
\mathrm{L} / \mathrm{M} \mathrm{P}\end{array}$ & $\begin{array}{l}\text { P/A } \\
\text { P/A M } \\
\text { P/A L }\end{array}$ & $\begin{array}{l}\mathrm{H} / \mathrm{D} \\
\mathrm{LL} / \mathrm{ML}\end{array}$ \\
\hline \multirow[t]{4}{*}{$\operatorname{LB} 1(24,0)^{b}$} & 350 & 328 & 371 & 545 & & 0.76 & 0.33 & 1.4 \\
\hline & 134 & 452 & 158 & 151 & 401 & 0.97 & 0.49 & \\
\hline & 157 & 222 & 46 & 68 & 409 & 0.33 & 0.16 & \\
\hline & 129 & 107 & 83 & 3 & & & & \\
\hline \multirow[t]{4}{*}{ LB $12(30,56)$} & 94 & 66 & 144 & 162 & & 2.2 & 0.84 & 1.4 \\
\hline & 94 & 47 & 143 & 256 & 192 & 2.3 & 0.94 & \\
\hline & 46 & 47 & 107 & 206 & 180 & 2.1 & 0.81 & \\
\hline & 61 & 118 & 131 & 125 & & & & \\
\hline \multirow[t]{4}{*}{ LB $13(30,56)$} & 284 & 121 & 87 & 246 & & 0.97 & 0.51 & 1.5 \\
\hline & 81 & 161 & 112 & 198 & 187 & 0.99 & 0.52 & \\
\hline & 51 & 147 & 63 & 83 & 194 & 0.92 & 0.49 & \\
\hline & 34 & 108 & 99 & 69 & & & & \\
\hline \multirow[t]{4}{*}{$\mathrm{LB} 14(30,56)$} & 260 & 287 & 462 & 504 & & 1.9 & 0.27 & 1.4 \\
\hline & 71 & 195 & 249 & 257 & 325 & 1.8 & 0.25 & \\
\hline & 56 & 106 & 137 & 218 & 384 & 2.1 & 0.28 & \\
\hline & 19 & 21 & 33 & 30 & & & & \\
\hline \multirow[t]{4}{*}{ LB $3(49,28)$} & 35 & 49 & 95 & 129 & & 2.7 & 1.4 & 1.0 \\
\hline & 24 & 79 & 141 & 137 & 185 & 2.7 & 1.3 & \\
\hline & 46 & 125 & 185 & 190 & 192 & 2.7 & 1.4 & \\
\hline & 33 & 47 & 168 & 133 & & & & \\
\hline \multirow[t]{4}{*}{ LB $17(51,56)$} & 57 & 66 & 163 & 183 & & 2.6 & 0.52 & 1.1 \\
\hline & 19 & 64 & 74 & 86 & 178 & 2.5 & 0.47 & \\
\hline & 15 & 30 & 67 & 67 & 166 & 2.9 & 0.55 & \\
\hline & 13 & 38 & 72 & 71 & & & & \\
\hline \multirow[t]{4}{*}{ LB $2(77,0)$} & 69 & 95 & 35 & 29 & & 0.93 & 1.0 & 0.48 \\
\hline & 76 & 163 & 93 & 35 & 340 & 0.48 & 0.55 & 0.37 \\
\hline & 47 & 112 & 164 & 54 & 341 & 1.7 & 2.0 & \\
\hline & 12 & 51 & 131 & 38 & & & & \\
\hline \multirow[t]{4}{*}{ LB $6(90,24)$} & 13 & 28 & 46 & 62 & & 3.5 & 0.89 & 0.49 \\
\hline & 6 & 30 & 90 & 82 & 191 & 3.6 & 0.94 & 0.91 \\
\hline & 8 & 40 & 93 & 75 & 189 & 3.4 & 0.88 & \\
\hline & 3 & 21 & 46 & 32 & & & & \\
\hline I.B $7(90,24)$ & 15 & 56 & 88 & 69 & & 3.4 & 1.3 & 0.48 \\
\hline & 10 & 51 & 123 & 106 & 302 & 2.9 & 1.1 & 0.88 \\
\hline & 9 & 59 & 137 & 128 & 316 & 3.9 & 1.4 & \\
\hline & 6 & 66 & 147 & 133 & & & & \\
\hline LB $8(90,533)$ & 10 & 49 & 62 & 66 & & 3.1 & 1.1 & 0.55 \\
\hline & 16 & 49 & 99 & 115 & 252 & 2.8 & 0.94 & 1.2 \\
\hline & 16 & 47 & & 135 & 239 & 3.5 & 1.2 & \\
\hline & 7 & 47 & 95 & 86 & & & & \\
\hline LB $4(96,0)$ & 21 & 66 & 36 & 18 & & 1.2 & 1.1 & 0.56 \\
\hline & 22 & 64 & 62 & 13 & 210 & 0.75 & 0.67 & 0.25 \\
\hline & 27 & 67 & 110 & 18 & 185 & 1.9 & 1.7 & \\
\hline & 3 & 19 & 74 & 21 & & & & \\
\hline LB $5(96,0)$ & 21 & 10 & 9 & 15 & & 1.4 & 1.9 & 0.17 \\
\hline & 15 & 15 & 32 & 16 & 322 & 1.2 & 0.56 & 0.53 \\
\hline & 6 & 12 & 51 & 24 & 290 & 3.2 & 1.5 & \\
\hline & 3 & 13 & 25 & 7 & & & & \\
\hline LB $10(104,533)$ & 4 & 6 & 4 & 4 & & 5.7 & 2.5 & 0.10 \\
\hline & 0 & 1 & 1 & 9 & 179 & 1.6 & 0.36 & 1.4 \\
\hline & 0 & 1 & 13 & 19 & 217 & 17 & 3.8 & \\
\hline & 0 & 3 & 18 & 18 & & & & \\
\hline LB $9(109,0)$ & 21 & 18 & 10 & 6 & & 1.2 & 1.9 & 0.62 \\
\hline & 30 & 38 & 39 & 16 & 119 & 0.66 & 1.2 & 0.48 \\
\hline & 21 & 52 & 69 & 32 & 104 & 1.6 & 2.9 & \\
\hline & 7 & 49 & 67 & 35 & & & & \\
\hline LB $11(115,533)$ & 13 & 15 & 16 & 30 & & 2.3 & 1.6 & 0.55 \\
\hline & 19 & 16 & 24 & 24 & 104 & 1.5 & 1.0 & 1.2 \\
\hline & 10 & 15 & 46 & 47 & 101 & 3.1 & 2.1 & \\
\hline & 10 & 28 & 46 & 56 & & & & \\
\hline
\end{tabular}

TABLE III-continued

\begin{tabular}{|c|c|c|c|c|c|c|c|}
\hline \multirow{2}{*}{$\begin{array}{c}\text { Animal } \\
\text { Name } \\
\text { (Postoperative) }\end{array}$} & \multicolumn{3}{|c|}{ Host Tectum } & \multirow[b]{2}{*}{$\begin{array}{c}\text { Donor } \\
\text { Tectum } \\
\text { (Midmedial) }\end{array}$} & \multicolumn{3}{|c|}{ Ratios } \\
\hline & Med & & Lateral & & $\begin{array}{l}\text { L/M } \\
\text { L/MA } \\
\text { L/M P }\end{array}$ & $\begin{array}{l}\mathrm{P} / \mathrm{A} \\
\mathrm{P} / \mathrm{A} \mathrm{M} \\
\mathrm{P} / \mathrm{AL}\end{array}$ & $\begin{array}{l}\mathrm{H} / \mathrm{D} \\
\mathrm{LL} / \mathrm{ML}\end{array}$ \\
\hline \multirow[t]{4}{*}{ LB $15(167,28)$} & 41 & 67 & $30 \quad 28$ & & 1.6 & 1.4 & 0.62 \\
\hline & 61 & 78 & $92 \quad 49$ & 237 & 0.81 & 0.65 & 0.74 \\
\hline & 18 & 72 & $135 \quad 99$ & 196 & 2.8 & 2.3 & \\
\hline & 4 & 66 & 116101 & & & & \\
\hline \multirow[t]{4}{*}{ LB $18(329,28)$} & 30 & 28 & $\begin{array}{ll}47 & 57\end{array}$ & & 3.4 & 1.5 & 0.55 \\
\hline & 47 & 54 & 118106 & 336 & 2.1 & 0.71 & 0.95 \\
\hline & 24 & 56 & 203177 & 374 & 5.4 & 1.9 & \\
\hline & 7 & 26 & 112115 & & & & \\
\hline \multirow[t]{4}{*}{ LB $19(330,28)$} & 92 & 119 & 181220 & & 2.1 & 0.82 & 0.76 \\
\hline & 60 & 127 & $154 \quad 147$ & 316 & 1.8 & 0.63 & 0.96 \\
\hline & 46 & 107 & 220164 & 260 & 2.6 & 0.93 & \\
\hline & 27 & 69 & 135133 & & & & \\
\hline \multirow[t]{4}{*}{ LB $20(330,28)$} & 72 & 76 & $52 \quad 66$ & & 1.8 & 1.2 & 0.52 \\
\hline & 79 & 110 & 139137 & 387 & 1.2 & 0.74 & 1.0 \\
\hline & 46 & 95 & 164141 & 301 & 2.6 & 1.7 & \\
\hline & 13 & 96 & 170179 & & & & \\
\hline
\end{tabular}

${ }^{a}$ For the $4 \times 4$ measurements, the left column is from the medial tectum, the right column is lateral, the top row is anterior, and the bottom row is posterior. See the text for details.

${ }^{b}$ The first number is days after deflection at time of labeling. The second number is days of enucleation prior to deflection.

from the insertion site. These two paths were also seen in all animals at later postoperative periods and so will be described in some detail. Except as noted the description of the pathway applies to both early and late postoperative times. In most fish the number of fibers taking each path was roughly equal, though in a few fish one or the other was substantially larger. In the first path the fibers grew up toward the tectal surface in a dorsal or dorsolateral orientation. Within a few hundred micrometers of the insertion site, nearly all of these fibers had returned to one of the normal optic layers of tectum. Many reached as far superficially as stratum opticum (SO), which is 25 to $50 \mu \mathrm{m}$ below the tectal surface, but the large majority entered the main innervation layer of the SFGS which is immediately beneath the SO. A smaller fraction of label was found in the two minor optic layers. One of these is halfway between the SFGS and the main deep cell layer, stratum periventriculare, and the other is immediately superficial to this same layer. Both of these optic layers are normally quite thin and lightly labeled. Their pattern of label essentially paralleled that of the SFGS and will not be referred to separately. Label in the SFGS was not the uniform homogeneous kind found in the mature innervation but was mainly in the form of dense spots which were a few micrometers in diameter. They were scattered throughout the SFGS of medial tectum (Fig. $2 A$ ). Some of the larger spots could be traced through serial sections all of which were frontal in orientation. It was evident that most of the spots were actually strings having a predominantly anteroposterior orientation. In short this label appeared to be fascicles of optic fibers. Similar anteroposterior fascicles were also seen in the SO, the place where they are normally found. The overall pattern of label of this group of fibers was very similar to that seen 

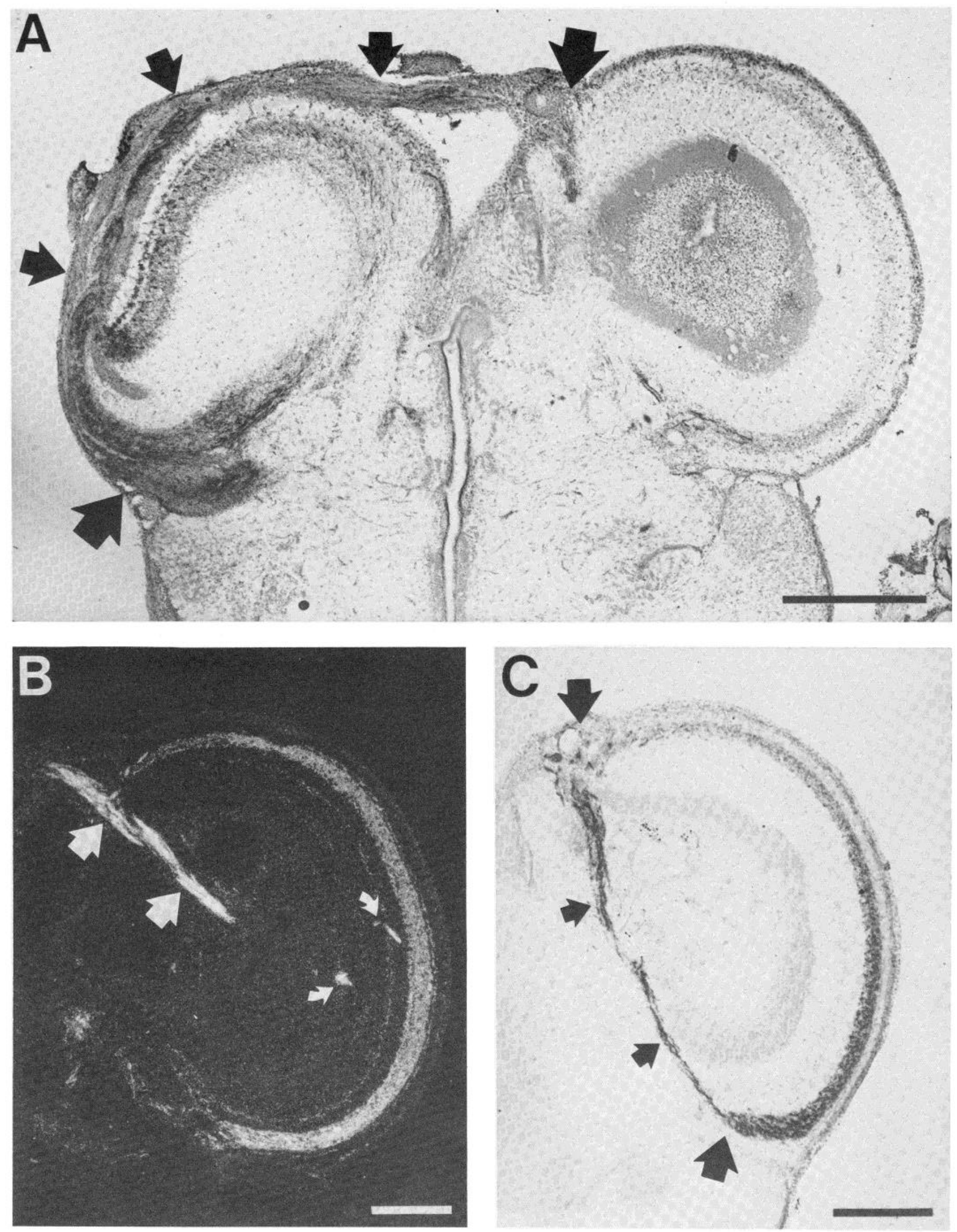

Figure 1. A, Frontal autoradiogram through the anterior region of both tecta in animal LB 8, illustrating the deflection surgery. Host tectum on the right had been denervated for 533 days prior to deflection followed by autoradiography 90 days later. Large 


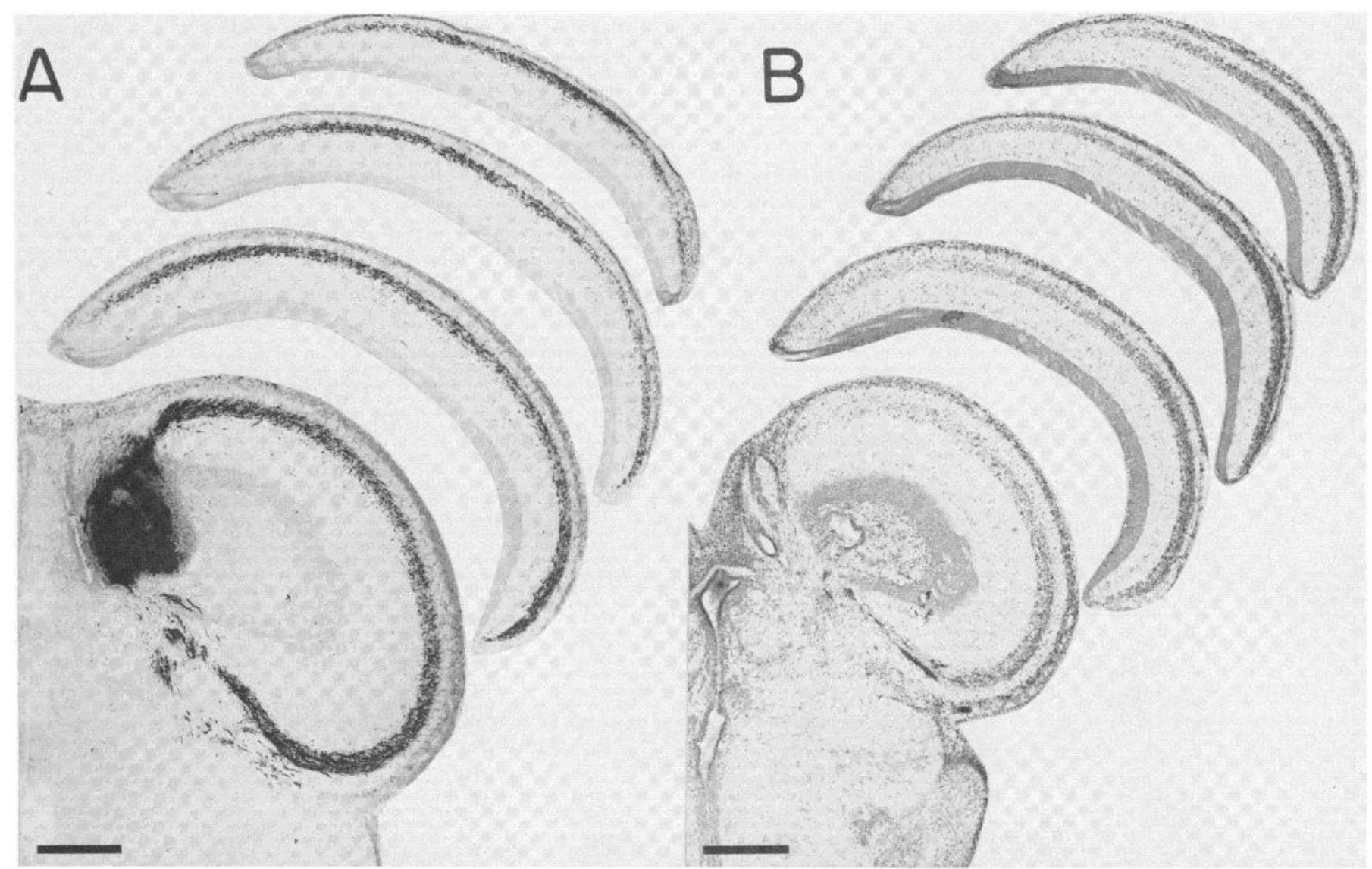

Figure 2. Photomontages of frontal autoradiograms of host tectum of two animals. For each montage the photomicrograph at lower left is through the insertion site. The three cutouts of tectum above and to the right were of progressively more posterior sections taken so as to divide tectum posterior to the insertion site into four equal parts (see "Materials and Methods"). Upper left, medial edge of the tectum; lower right, lateral edge. Bar, $400 \mu \mathrm{m}$. A, Fish LB 13 in which enucleation was for 56 days prior to deflection and autoradiography was 30 days later. At this early time substantial label is distributed across the entire tectum in both medial and lateral halves. Fibers in medial tectum have not yet grown into the lateral half. $B$, Fish LB 7 in which enucleation was at 24 days before deflection and autoradiography was at 90 days after deflection. By this time label was clearly concentrated in the lateral half and within the lateral half was heavier posteriorly than anteriorly.

following deflection of medial fibers (Meyer, 1979), except possibly for an overall lateral shift in the position of the label. This path will be referred to as the medial route.

The second path taken by fibers leaving the insertion site was a highly unusual one (Fig. $1 B, C$ ) in that it has never been seen when medial fibers were deflected (Meyer, 1978a, 1979). Fibers took a fairly direct path, in essence a shortcut, to lateral tectum. The overall orientation of this path was ventral and lateral and will be referred to as the ventrolateral route. In its most dramatic form, seen in one fish at this early time and in two later fish, fibers grew ventrally from the insertion site, i.e., away from the optic layers of tectum and into foreign regions. They traversed through the periventricular layer of anterior tectum and, in a few cases, through part of the underlying tegmentum until reaching the lateral tectal margin (see Fig. $1 C$ for an example in a later fish). In one animal in this early group (and one fish in the later group; see Fig. $1 B$ for an example in a later fish),

arrowhead at lower left, lateral region of donor tectum posterior to which optic fibers had been dissected free of tectum. As indicated by the series of small arrowheads, those fibers were redirected over the lateral and dorsal surface of donor tectum, across the midline, and into the medial edge of host tectum indicated by the upper large arrow. A few fibers can be seen entering host tectum, but the main entry point was more posterior and is shown in $B$. Bar, $400 \mu \mathrm{m}$. $B$, Same animal as in $A$ but section is of host tectum and is more posterior so as to be through the main entry point of deflected fibers indicated by larger arrow. A large diagonal shaft of white grains (dark-field illumination) can be seen running to lower right. The more distal parts of this path are indicated by small arrows. It appears that in this fish most deflected fibers had grown directly to middle lateral tectum. The semicircular band of grains seen near the tectal surface is the main optic innervation layer. Note that more grains are in the lateral regions of this layer. Bar, $400 \mu \mathrm{m}$. C, Autoradiogram through the insertion site into host tectum of fish LB 17 . Denervation was 56 days prior to deflection, and autoradiography followed 51 days later. This illustrates the more typical path of deflected fibers, nearly all of which are captured on one section here. Upper large arrow, insertion site. A large downwarddirected band of deflected fibers has taken a "shortcut" to the far lateral edge of the tectum (arrow at lower right). Again note that the grains in the main innervation near the tectal surface are predominantly in the lateral half. $B a r, 400 \mu$ m. 
there was an additional group of fibers that grew from the insertion point to about the middle of the lateral half of the tectum rather than to the lateral edge. Some of these fibers could be traced up through the deep layers of tectum, including the periventricular layer, and into the optic layers of tectum. These paths through foreign, i.e., nonoptic, regions of midbrain were up to $1000 \mu \mathrm{m}$ or more long. In most fish, however, fibers taking the ventrolateral route tended to minimize their path through nonoptic territory. In these cases (Figs. 2 to 4), fibers grew $100 \mu \mathrm{m}$ or so anteriorly from the insertion site and turned ventrolaterally near the anterior end of tectum where the distance to the lateral edge was less. This path was closely associated with or within the normal optic pathway; however, the direction of growth, dorsal to ventrolateral, was highly anomalous. Once at lateral tectum the pathway was typical of regenerating fibers. Fibers entered the optic layers of lateral tectum and grew posteriorly within these layers. Much of this label in lateral tectum was also fasciculated in appearance. In both the medial and lateral tectum, i.e., for fibers taking either path, label stretched in decremental fashion to the posterior end of tectum where the amount of labeling was noticeably less than in anterior tectum.

Densitometric data (Table III) were obtained and the various ratios calculated as above except that instead of a medial/lateral ratio, a lateral/medial ratio $(\mathrm{L} / \mathrm{M})$ was determined. The lowest $\mathrm{L} / \mathrm{M}$ was for the 24-day fish at 0.76 . The values for the three 30 -day fish were $0.97,1.9$, and 2.2. The L/M-P (lateral to medial-posterior) and L/ M-A (lateral to medial-anterior) for the 30-day fish were both quite close to the overall $\mathrm{L} / \mathrm{M}$ ratio for each fish. For the 24-day fish, however, L/M-P was low (0.37) compared with an $\mathrm{L} / \mathrm{M}-\mathrm{A}$ of 0.97 , probably reflecting the initial arrival of fibers in the medioposterior quadrant which is closer to the insertion site than the lateroposterior quadrant. For all four early fish the P/A ratio ranged from 0.27 to 0.84 . The early predominance of anterior over posterior label implies that fibers were still in the process of growing into the posterior half. The increased axoplasmic transport as indicated by $\mathrm{H} / \mathrm{D}$ ratios of 1.4 to 1.5 as well as any increased labeling of fibers of passage at this early time may have also contributed to the low P/A.

The two fish at 49 and 51 days might be considered a transition group between the early group and those at 77 days and later. The H/D indices were 1.0 and 1.1 , respectively, values that fell between the earlier and later fish. The pattern of tectal labeling of the 51-day fish was reminiscent of the 30 -day fish. Its $\mathrm{P} / \mathrm{A}$ was 0.52 , comparable to the early group and much lower than that for any later fish. The 49-day fish resembled the later group
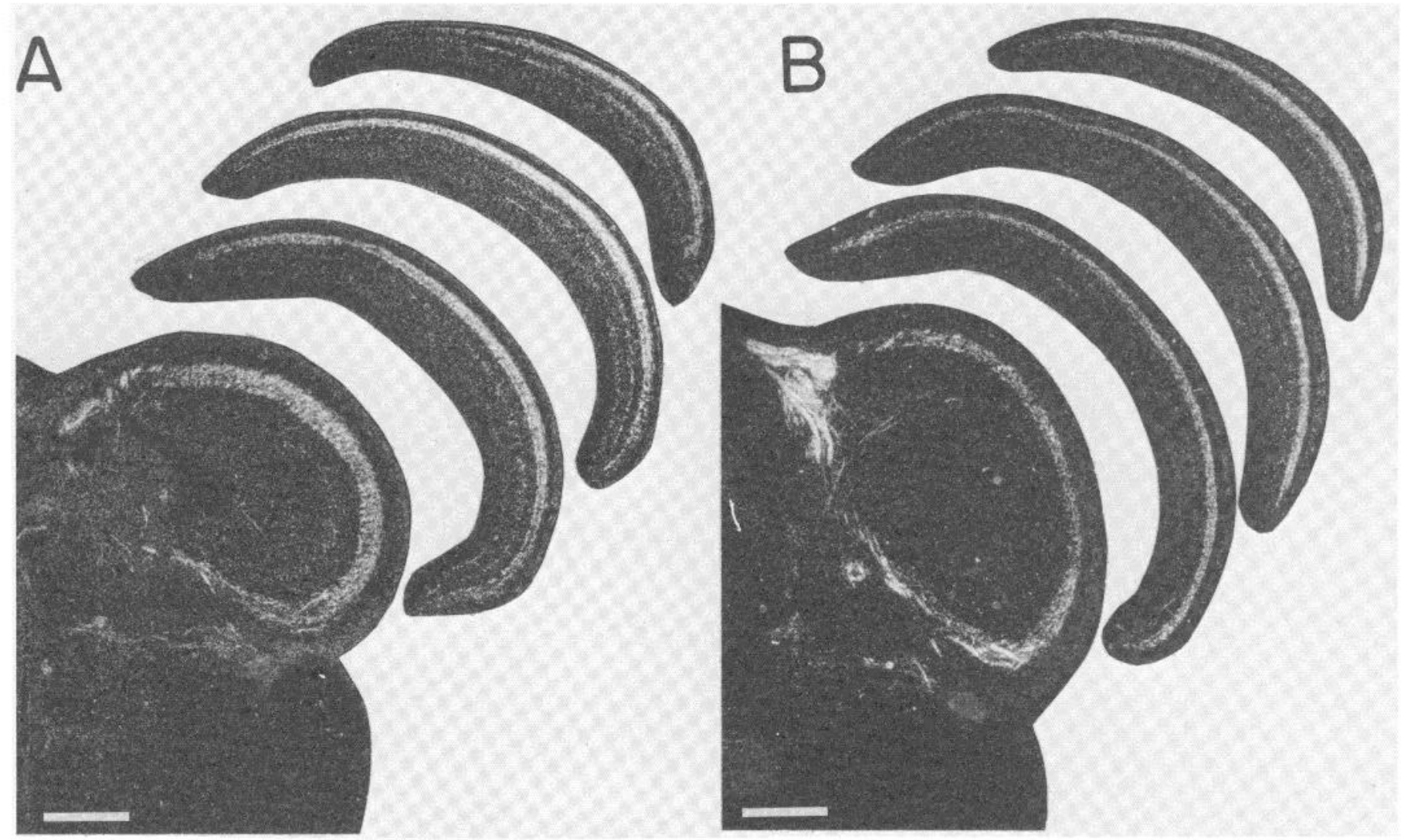

Figure 3. Photomontages as in Figure 2, but in dark field. A, Fish LB 4 in which deflection and enucleation of host eye were simultaneous. Autoradiography was 96 days later. Label is predominantly in the lateral half and heavier posteriorly than anteriorly. However, note the medial anterior shift in label compared with Figures $2 B, 3 B$, and $4 A$ in which enucleation preceded deflection. The lateral edge and posterior end are less densely labeled. B, Fish LB 11 in which 533 days of denervation of host tectum preceded deflection. Autoradiography was 115 days after deflection. The distribution of label is clearly preferential, being greatest in the lateroposterior quadrant. 


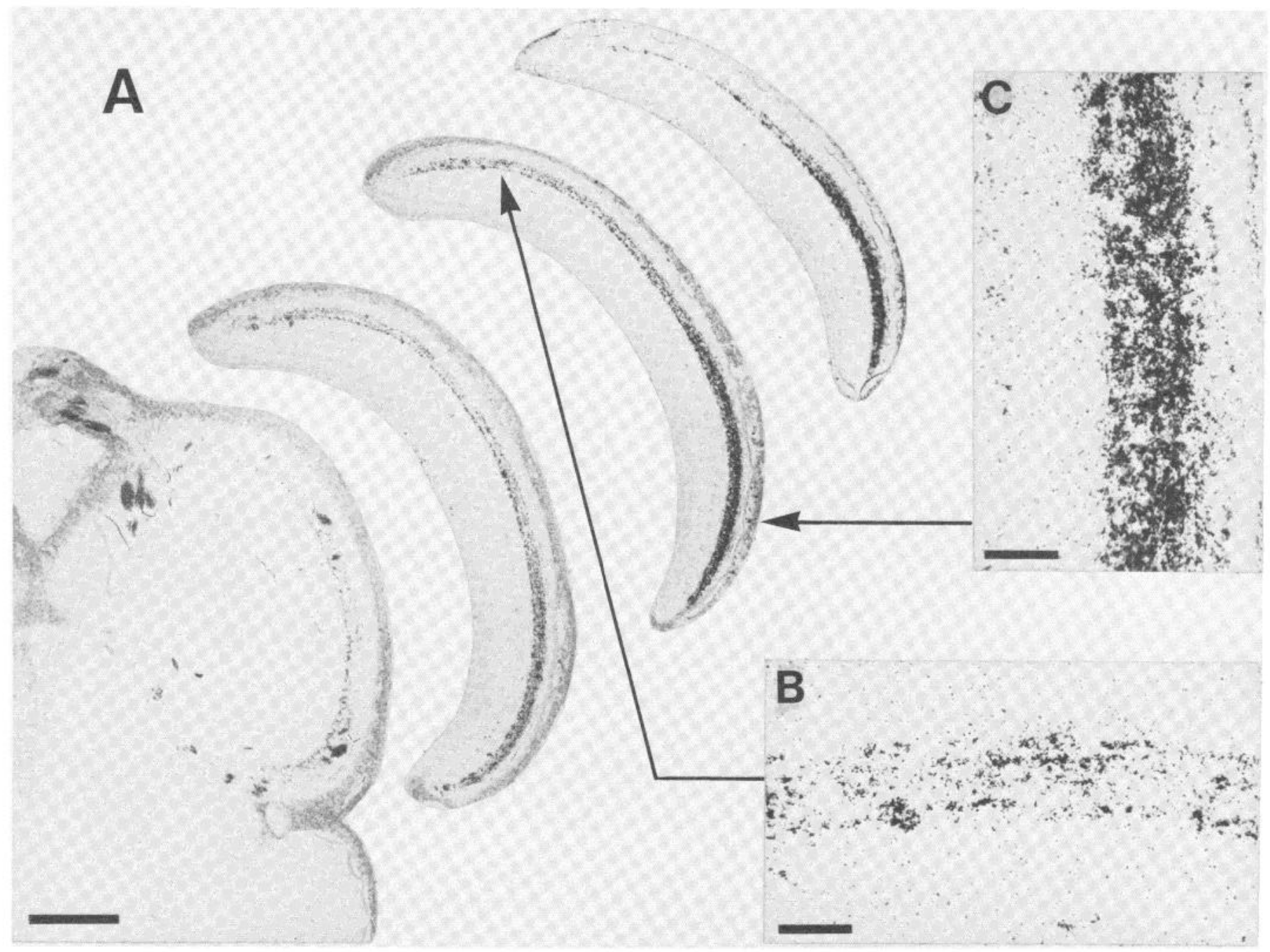

Figure 4. Fish LB 18 in which enucleation was 28 days prior to deflection and autoradiography was 329 days after deflection. A, Photomontage as in Figures 2 and 3. Lateroposterior preferential labeling is apparent even at this long postoperative period. $B$, High magnification of the medial region from section 3 (arrow). Note that label is not distributed throughout the main innervation layer but is mostly concentrated into clumps which are presumably fascicles of fibers of passage. Bar, $50 \mu$ m. $C$, High magnification also of section 3 but of lateral region (arrow). Grains fill the innervation layer. Also note the thin band of grains above this layer (to the right). This layer was seen in most animals but only in lateral regions of tectum.

having a $\mathrm{P} / \mathrm{A}$ of 1.4 . In each case the $\mathrm{P} / \mathrm{A}-\mathrm{M}$ and $\mathrm{P} / \mathrm{A}-\mathrm{L}$ were comparable to the P/A. For both fish lateral label predominated with $\mathrm{L} / \mathrm{M}$ ratios of 2.6 and 2.7 , respectively. L/M-A and L/M-P were comparable.

Fish from 77 to 330 days after deflection comprise the late group. The grain density in the regenerated fibers as compared to the intact ones in donor tectum was no longer elevated. The average $\mathrm{H} / \mathrm{D}$ was $0.5 \pm 1.8$. Most of this variation can be attributable to three exceptional individuals. Two fish, LB 5 and LB 10, had H/D ratios of 0.17 and 0.10 , respectively. These fish were also judged anatomically to have had the fewest successfully deflected fibers; i.e., the deflected bundle was the smallest. For the third fish, LB 18, the H/D ratio was 0.76 . This was apparently the largest deflection as judged by the size of the actual deflected bundie and the extent of damage to donor tectum. This was also indicated by the electrophysiology (see below). The remaining 10 fish had $\mathrm{H} / \mathrm{D}$ ratios of 0.48 to 0.62 , with an average of $0.54 \pm$
0.05 . In spite of this difference in H/D between these 10 fish and the 3 above, the overall pattern of label in host tectum was similar for all fish. However, LB $10(\mathrm{H} / \mathrm{D}=$ $0.10)$ had by far the most selective innervation of any fish, raising the possibility that other factors may have been operating in this case. To avoid any bias in favor of selectivity, this fish was excluded from the averages reported below, though in fact the averages were not greatly affected by its inclusion. String-like label was also further reduced, but it was still possible to see medial and ventrolateral routes, both of which persisted in each fish. All the ventrolateral paths were directed to the lateral edge except in the one fish similar to the one described for the early group in which some of the ventrolateral fibers grew to a more medial region of lateral anterior tectum (Fig. $1 C$ ).

As a group fish which had been enucleated for 24 to 533 days prior to deflection (Figs. $2 B, 3 B$, and 4 ) appeared qualitatively different than those with simultaneous enu- 
cleation and deflection and will be described first. In all of these fish the densest and most normal looking label was in the posterolateral quadrant of the tectum. In this region grains filled the SFGS in homogeneous fashion as is typical of innervation-type labeling. Elsewhere, label was generally less dense though often substantial and was not as uniformly dispersed within the SFGS. Instead, label was often concentrated in the SO, and that which was in the SFGS was often in clumps or strings suggesting fascicles from fibers of passage (compare Fig. $4 B$ and Fig. $4 C$ ). In some cases (Fig. $3 B$ ) these fascicles were large. The overall thickness of the label in the SFGS outside the lateroposterior quadrant was noticeably diminished compared to that in the lateroposterior quadrant. The amount of this label outside the lateroposterior quadrant varied with tectal position. For the medial half of the tectum most label was in the general vicinity of the insertion site, covering much of the anterior third of the tectum. More posteriorly, the amount of label in the medial half progressively declined, especially near the medial edge, so that in the posterior third label in the medial half was typically sparse. In the lateral half labeling of the anterior tectum was variable, ranging from obviously lighter than posterior labeling to nearly the same. The transition between lateroposterior label and label in surrounding tectal regions was a very gradual one for the SFGS and for the two minor lamina beneath the SFGS. There were no sharp demarcations between tectal regions, but rather a gradient-wise change in the density and character of label that occurred over several hundred micrometers. The exception to this graded transition of labeling was the selective appearance of a third minor lamina that is immediately superficial to the SO. This very thin light layer of grains is normally distributed across the entire tectum. Though it was not detectable in lightly labeled fish or in fish at the early stages of regeneration ( 24 to 30 days after deflection), it was clearly identifiable in nine fish with the heaviest labeling of host tectum, presumably those with the largest deflection. This optic layer was almost entirely restricted to the lateroposterior quadrant. The medial-to-lateral transition was virtually all or none. The layer stopped abruptly at or before halfway along the mediolateral axis of host tectum and could not be detected in the medial half. In lateroanterior tectum the layer made a sporadic appearance in those fish with the heaviest anterolateral labeling. The lateroposterior quadrant was the only region where, when it was detectable, the layer always occurred.

The densitometric measurements and the various ratios were also averaged for this group, excluding LB 14 for reasons mentioned above. The average $\mathrm{L} / \mathrm{M}$ was 2.6 \pm 0.78 . With one minor exception (LB 8) $\mathrm{L} / \mathrm{M}$ in the posterior half (L/M-P) for each individual animal was higher than $\mathrm{L} / \mathrm{M}$ for the anterior half $(\mathrm{L} / \mathrm{M}-\mathrm{A})$. The average $\mathrm{L} / \mathrm{M}-\mathrm{P}$ was $3.4 \pm 0.92$ compared to the $\mathrm{L} / \mathrm{M}-\mathrm{A}$ of $2.1 \pm 0.95$. The average $\mathrm{P} / \mathrm{A}$ was $1.2 \pm 0.28$, indicating that overall there was only slightly greater posterior labeling than anterior labeling. However, this did not generalize to the medial and lateral halves considered separately. With the sole exception of the same animal mentioned above (LB 8), P/A for the lateral half was higher than the P/A for the medial half. P/A-L was 1.6 \pm 0.53 compared to a $\mathrm{P} / \mathrm{A}-\mathrm{M}$ of $0.84 \pm 0.18$. Thus, in the medial half there was more label anteriorly than posteriorly. In the lateral half there was more label posteriorly than anteriorly which was actually greater than the overall $\mathrm{P} / \mathrm{A}$. The above ratios and a set of normalized and averaged densitometric measures for this group are given in Table IV.

The late group of four fish in which enucleation was done on the same day as deflection (Table III) were grossly similar to the above group in which enucleation preceded deflection. Both the ventrolateral and medial routes could be detected; consequently, there was substantial labeling in the lateral half. However, in three fish (LB 7, LB 11, and LB 14) there was nearly as much medial as lateral label. The average $\mathrm{L} / \mathrm{M}$ was only $1.3 \pm$ 0.42 . Like the preceding group $\mathrm{L} / \mathrm{M}$ for the posterior half was for each animal greater than the $\mathrm{L} / \mathrm{M}$ for the anterior half. The average $\mathrm{L} / \mathrm{M}-\mathrm{P}$ was $2.1 \pm 0.31$. Thus, for the anterior half there was, on the average, more medial label than lateral label. In contrast the overall posterior over anterior labeling was, if anything, more asymmetrical than the preceding group, with an average $\mathrm{P} / \mathrm{A}$ of $1.5 \pm$ 0.49 . Again, this preferential increase in posterior label held mainly for the lateral half. In fact the lateral-medial difference in $\mathrm{P} / \mathrm{A}$ was greater than in the above group with prior enucleation. The average $\mathrm{P} / \mathrm{A}-\mathrm{M}$ was $0.75 \pm$ 0.31 which was less than the above group, and the average $\mathrm{P} / \mathrm{A}-\mathrm{L}$ was $2.0 \pm 0.62$ which was greater than the above group. Closer examination of the autoradiograms revealed a qualitative difference between these four fish and the preceding eight fish. The area of densest label appeared to be shifted anteromedially. Specifically, the peripheral rim of the lateroposterior quadrant was consistently less densely labeled than the more medioanterior regions of the quadrant. This rim of relatively light labeling was several hundred micrometers wide and included both the lateral and posterior edges. In contrast, in the fish with prior enucleation the lateroposterior rim was among the most heavily labeled areas of tectum. To quantitate this difference between the two groups, the fourth column of densitometric measurements which were taken near the lateral edge were summed and divided by the sum of the third column (LL/LM). For the group of eight fish with prior enucleation, LL/LM ranged from 0.74 to 1.2 with an average of $0.98 \pm 0.16$. In other words the density of label was about the same near the lateral edge as it was more medially within the lateral half. For the group with simuitaneous enuleation and deflection, LL/LM ranged from 0.25 to 0.53 with an average of $0.41 \pm 0.12$; i.e., there was on the average 2.4 times more label in the medial part of the lateral half of tectum compared with the lateral edge. All of the above computations are given in Table IV along with the normalized average densitometer reading for the last four fish. Also included are the pooled ratios for these last four fish and the preceding eight fish.

Three fish were mapped electrophysiologically (Fig. 5). Most of the lateral half of tectum was not accessible to superficial probing, and recording from this region proved difficult to do. Although tangential penetrations through lateral tectum were done, most penetrations were made in the medial half at $240-\mu \mathrm{m}$ intervals. Because of this limitation the main goal was to determine 
TABLE IV

Densitometry summary

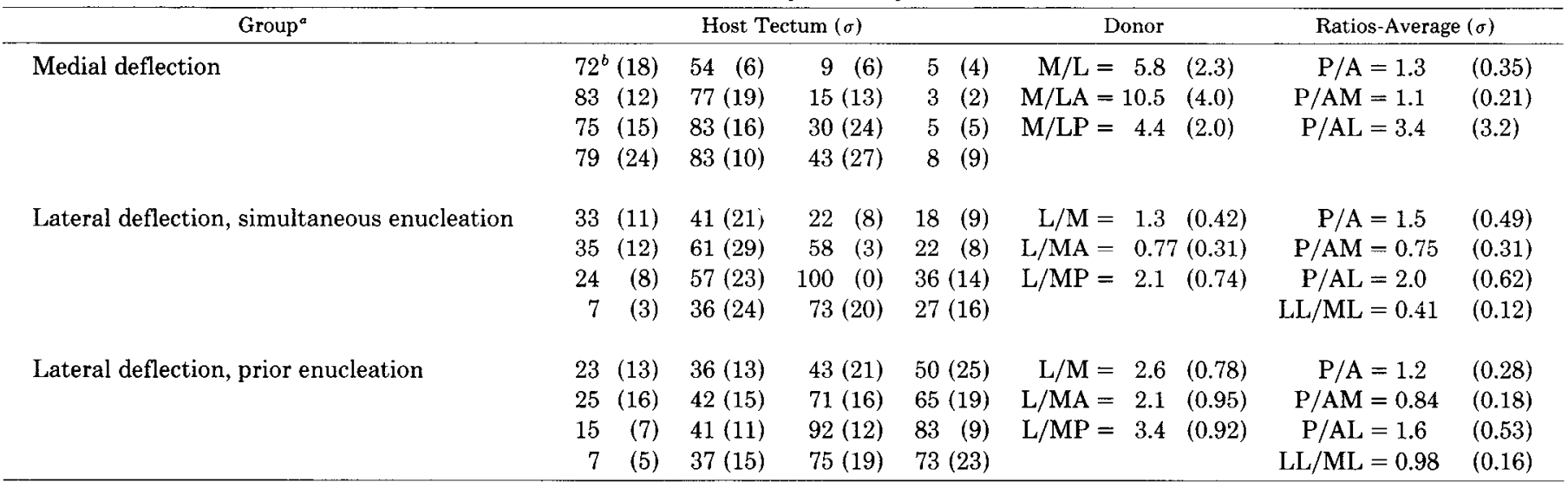

${ }^{a}$ Excluding animals at short, postoperative times: MB 7, LB 1, LB 12, LB 13, LB 14, LB 3, LB 17, and also LB 10 . See the text.

${ }^{b}$ Conventions are the same as for Tables II and III. The normalization procedure is described in the text.

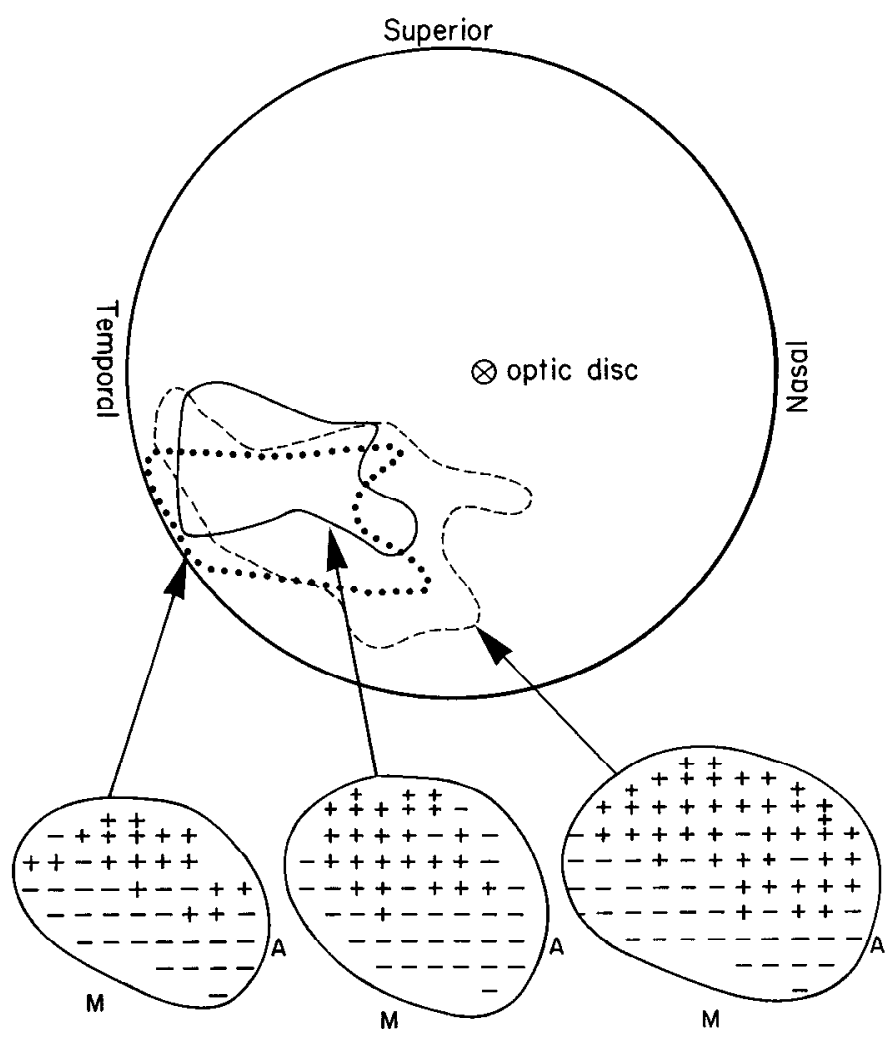

Figure 5. Summary of electrophysiology. Large circle at top, $180^{\circ}$ of visual field with the position of the projected optic disc indicated. The area of visual field in which receptive fields were located is bounded by a line for each fish. ...., LB 18; —, LB $15 ;----$, LB 19. Bottom, outlines of corresponding tecta as seen in dorsal view. Medial $(M)$ and anterior $(A)$ are indicated. Each "-" indicates a tectal position from which no unit responses were obtained. Each "+" is the site of unit responses. The probing interval across the tectum was $500 \mu \mathrm{m}$ (shown) or less (not shown).

the retinal origin of the deflected fibers, in particular to determine whether medial fibers which should be recordable in medial tectum were inadvertently deflected. In most cases receptive fields were confined to the inferiortemporal visual field except for a 10 to $20^{\circ}$ intrusion into the inferior-nasal field in one animal. No units from the superior field were detected. In the medial half of the tectum, units were obtained in only about half of the penetrations and were mainly at the anterior and lateral regions. Near the medial edge and in the posteromedial quadrant, few or no units were obtaincd. In accordance with a previous study in which relatively few fibers were deflected into a denervated tectum (Meyer, 1978a), retinotopography was of low order.

Histological examination of donor tectum for the origin of deflected fibers corroborated the above electrophysiology (Fig. 6). No damage to the medial brachia of the optic tract could be detected. Surgical disruption of the lateroposterior part of the optic path through lateral tectum was always evident, and a variable degree of damage to its more anterior parts was not unusual. On the basis of histology, electrophysiology, the anatomy of the optic pathway, and the above autoradiography, it is likely that deflected fibers included lateroposterior fibers, may have included neighboring lateroanterior fibers, but never included medial fibers.

\section{Discussion}

Normally, fibers which innervate posteromedial tectum approach tectum through the medial brachia of the optic tract, enter tectum near its anteromedial edge, and course posteriorly into the posteromedial quadrant of tectum. When tectum is denervated of all optic fibers and then optic fibers which normally innervate posteromedial tectum are surgically inserted into tectum near its anteromedial edge, these fibers grow posteriorly into posteromedial tectum. The lateral half of the tectum is left sparsely labeled. In contrast when fibers which normally innervate posterolateral tectum are inserted into this same anteromedial position in a similarly denervated tectum, these fibers preferentially innervate the posterolateral quadrant over the posteromedial quadrant which is left with sparse labeling.

These posterolateral fibers follow two distinguishable routes. Some grow posteriorly in a lateral direction toward the posterolateral tectal quadrant. A comparable number of fibers initially grow laterally and sometimes 

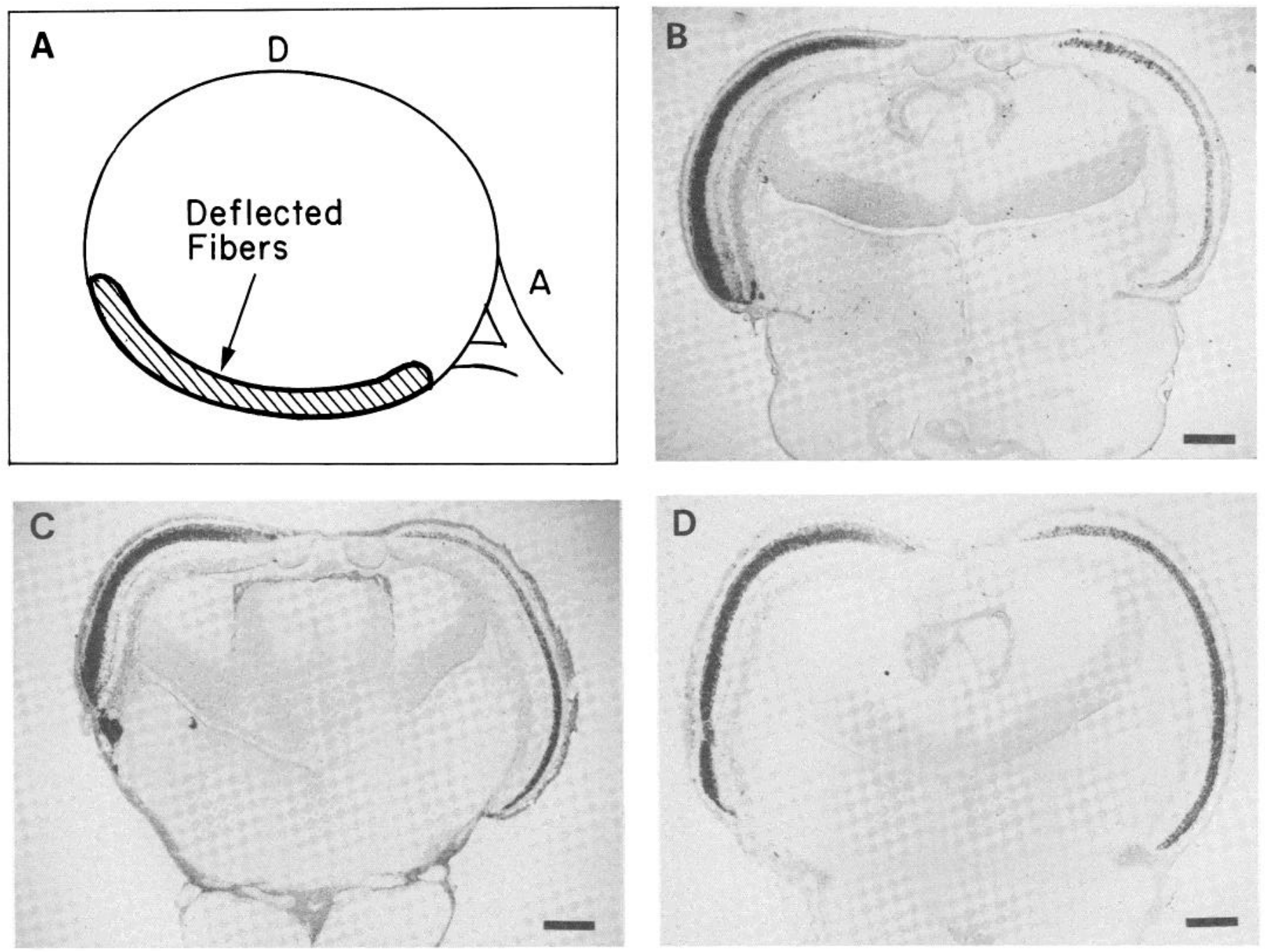

Figure 6. A, Schematic of donor tectum as seen in side view showing the tectal region from which deflected fibers were taken. Anterior $(A)$ is to the right and dorsal $(D)$ is at top. The branching structure at the anterior end denotes the brachial division of the optic tract. The deflected fibers are derived exclusively from the lateral division. $B, C, D$, Low-power autoradiograms showing both donor (left) and host (right) tecta. $B, \mathrm{LB} 15 ; C, \mathrm{LB} 18 ; D, \mathrm{LB} 19$ (the three fish on which electrophysiological measurements were obtained (Fig. 5)). Sections are taken at approximately the anterior third along the anterior-posterior tectal extent. Damage to donor tectum indicating the area from which deflected fibers were taken can be estimated from comparison with host tectum. Bar, $500 \mu \mathrm{m}$.

anteriorly to the lateroanterior edge of the tectum, and subsequently follow a posterior path. The latter path mimics the normal path of posterolateral fibers which approach tectum through the lateral brachia of the optic tract to enter the anterolateral tectum. This differential and appropriate growth of identically treated medioposterior and lateroposterior fibers, in the absence of other optic fibers, indicates the existence of markers in optic fibers and in tectum that mediate selective growth. Furthermore, since the innervation pattern by deflected lateroposterior fibers is just as selective when host tectum is denervated of optic fibers for as long as 533 days, the tectal properties which mediate selective innervation would seem not to require optic innervation for their maintenance. On the other hand, the pattern of inappropriate labeling indicated that the initial position and growth path exerted a significant influence. In the case of medioposterior fibers, substantial labeling occurred in the anteromedial tectum into which fibers were inserted and through which fibers grew to the posteromedial tectum. In the case of lateroposterior fibers, there was significant inappropriate label in anteromedial tectum, the insertion site, and in anterolateral tectum through which many fibers grew. In addition, fibers exhibited apparent reduced mediolateral selectivity in a simultaneously denervated tectum as compared to a tectum which was denervated by optic fibers for 3 weeks or more.

Selectivity of fiber growth. There are two technical considerations concerning autoradiography that should be mentioned. Although labeling preferentially accumulates at the terminals of fibers, especially at the short survival time used here $(18 \mathrm{hr})$, some fraction is distributed along the shafts of fibers. It is likely that the latter labeling contaminated the densitometric measurements, 
particularly in anterior tectum where the labeling pattern resembled fibers of passage. In the present experiment this would lead to an underestimate of selectivity. To be safe then, the contribution of fiber of passage will be ignored in this part of the discussion. The other related consideration is that labeling is no guarantee of synapses. From previous work (Cowan et al., 1972) it is likely that synapses are formed in regions with termination-type labeling, and this is further indicated by the correlation between electrophysiological responses with this type of label. However, for the present purposes it need only be assumed that the amount of labeling is related to the number of fibers that have invaded and in some manner distributed themselves in a given tectal region.

The case for mediolateral selectivity is clearer than that for selectivity along the anteroposterior axis and will be considered first. Two kinds of arguments for labelmediated growth can be made. One is that the main alternative explanations for directed fiber growth cannot explain the preferential distribution of lateroposterior fibers in the lateral half of tectum. The initial position of deflected fibers should result in preferential medial labeling. Also, the optic pathway and guidance structures followed by optic fibers should lead to labeling along the anteroposterior axis of the medial half of tectum, and in the case of long optic denervation prior to deflection the glial channels in the SO, which are the main candidate guidance structures mediating anteroposterior growth, would have degenerated (Murray, 1976; Murray and Edwards, 1982). Interfiber interactions with optic fibers from other retinal quadrants are simply not possible, nor is it reasonable to entertain selective interactions with degeneration debris in the fish in which there was a long period of optic denervation before deflection (Murray, 1976; Murray and Edwards, 1982). The second kind of argument is that medioposterior fibers and lateroposterior fibers exhibited very different growth patterns even though they were introduced into the same tectal position, and the direction of this differential growth correlated with the normal innervation pattern of the deflected fibers. This implicates the existence of an intrinsic difference, i.e., differential marker, in medioposterior and lateroposterior fibers as well as a related tectal marker which together mediated mediolateral preferential growth.

Preferential anteroposterior growth is less clear. Posterior labeling was, on the average, only slightly greater than anterior label. However, this does not mean that an anterior over posterior preference was largely lacking in these fibers. One must explain why large numbers of fibers invaded the posterior half of tectum after being inserted into the anterior half instead of simply staying in anterior tectum. One might argue that the anteroposterior guidance structures promoted posteriorly directed growth. This could explain the results of medioposterior deflection but is more difficult to reconcile with results from lateroposterior deflection. In the latter case label remaining in the medial half of the tectum where fibers had ready access to these guidance structures was heavier anteriorly than posteriorly. In the lateral half where access to these structures would seem less straightforward, posterior label was greater than anterior label and this difference was greater than for the tectum as a whole. Mechanical guidance cannot explain the anteroposterior labeling pattern in any simple way. An alternative explanation might be that fibers simply have a tendency to expand into available tectal space as a result, for example, of repulsive interactions between fibers (Udin, 1978; Fraser and Hunt, 1980). However, results from eye lesion studies indicate that the magnitude of such expansion would be insufficient to account for the present findings. When a surgically formed temoral half-retina reinnervates an intact tectum (Meyer, 1975; Schmidt et al., 1978; Strumer, 1981), the bulk of labeling is confined to the appropriate anterior half of tectum. Label declines across the posterior half after leaving the posterior quarter with little or no label. Since the number of fibers in the present deflection study was lower than in the eye lesion studies, expansion from a general fiber-fiber repulsion would be unlikely.

A more straightforward explanation is that deflected posterior fibers grew into posterior tectum because markers directed this posterior growth. This explanation would also fit with the tectal graft experiments in which fibers frequently (but not always) made the correct anteroposterior choice onto rotated or translocated tectal fragments (Sharma and Gaze, 1971; Yoon, 1973; Jacobson and Levine, 1975; Rho and Hunt, 1980). The presence of some deflected fibers in the anterior half of tectum here cannot he taken as evidence against anteroposterior markers. It may mean only that these markers are insufficient to entirely overcome the initial bias imposed by the insertion of fibers into anterior tectum. Posterior fibers may have limited capacity to bypass denervated anterior tectal regions when there is no competition from anterior fibers. This plasticity along the anteroposterior axis may be essential to accommodate anteroposterior shift in the projection that is thought to occur normally in juvenile and adult goldfish as a consequence of continued retinal (Johns and Easter, 1978; Meyer, 1978b) and tectal (Meyer, 1978b) growth.

Simply testing for the existence of retinal and tectal labels was not the only purpose of this study because there was already considerable evidence for markers from previous regeneration and developmental studies (see Attardi and Sperry, 1963; Fraser and Hunt, 1980; Conway et al., 1980; Meyer, 1982a). However, in these previous studies other factors such as interfiber interactions and pathway guidance were in operation which could be expected to enhance or alter the selectivity of innervation. Consequently, it is difficult to estimate the magnitude of the contribution from marker-mediated growth. Such an estimate is possible from the present study because the other major factors thought to promote selectivity were either eliminated (interfiber interactions with other retinal quadrants) or would be expected to work against selectivity (initial position and pathway guidance). Under these conditions preferential growth was expressed, but the resulting selectivity was relatively low. In the best group (fish with denervation prior to deflection), lateral labeling was only 2.6 greater than medial. The anterior-posterior difference was lower with $\mathrm{P} / \mathrm{A}$ of 1.5 in the best group (fish with simultaneous enucleation). This selectivity is much lower than that 
seen in the normal innervation where errant innervation is almost entirely absent. This low selectivity does not necessarily mean that the markers themselves are of low specificity; i.e., it does not mean that the number of discrete readable addresses in retina and tectum are few. Since we can only infer markers from the behavior of fibers, it remains possible that the specificity of markers (number of discrete addresses) is quite high, but the ability of fibers to translate these addresses into selective growth is impeded by other factors such as incorrect starting position or by the absence of other factors like interfiber interactions. However, one can say that, under the experimental conditions here which minimized the useful contribution of these other factors, the translation of these markers into an innervation (distribution) pattern is low in resolution.

The last point concerning selectivity regards its longterm stability. The projection was not detectably changed for 11 months and, in fish in which host tectum was denervated of optic fibers for 18 months prior to deflection, preferential innervation was observed. The findings counterindicate fiber remnants or degeneration debris as the basis of selectivity. Electron microscope observations (Murray, 1976; Murray and Edwards, 1982) on the tectum of goldfish have shown that nearly all severed optic fibers and associated debris are eliminiated within the first few weeks. If remnants or debris mediated selectivity, one would expect no selectivity after a long period of optic denervation and the best selectivity when deflection and denervation were simultaneous. Instead, selectivity was better when denervation preceded deflection.

These results also run counter to the notion that tectal markers require optic fibers for their maintenance. The evidence thought to indicate marker lability came from a series of electropysiological studies on surgically formed half-retinas in goldfish (Schmidt et al., 1978; Schmidt, 1978). Initially, a nasal half-retina was found to project only to its appropriate anterior half-tectum, but by 6 months responses could be obtained across the entire tectum. Alternatively, when tectum was denervated of all optic fibers for 6 months and then innervated by the ipsilateral nasal half-retina, responses were recorded across all of tectum. It was suggested that tectal markers were lost in about 6 months (Schmidt, 1978). However, the interpretation of these interesting electrophysiological observations is complicated by a lack of correspondence with anatomical studies. Three autoradiographic studies on nasal half-retinas (Meyer, 1975; Schmidt et al., 1978; Strumer, 1981) indicated that the large majority of optic fibers remained in the anterior half of the tectum indefinitely. At any rate, in view of the present findings, these nasal half-retina studies seem better interpreted in the context of tectal markers which to a considerable extent are stable and independent of optic innervation. Other processes could produce the time-dependent physiological changes seen in these previous studies. Some possibilities are discussed elsewhere (Meyer, 1982a).

Position biasing. The distribution of label suggests that deflected fibers favored terminations at or near their entry point and along their growth paths. In the case of medioposterior fibers, there was substantial label in anteromedial tectum where fibers were inserted and sub- stantial label stretching posteriorly into the medioposterior quadrant along the route to this quadrant. In the case of lateroposterior fibers, there was again substantial anteromedial label. The remaining label can be considered to lie along a broad diagonal path stretching between the entry point and the lateroposterior tectum including some lesser lateroanterior labeling. This again correlates with the entry point and with the subsequent growth path as far as can be determined with autoradiography. This labeling pattern suggests that position and pathway influence but do not wholly determine the pattern of innervation. This has been referred to elsewhere as position biasing (Meyer, 1982a) and has been discussed in detail. Although this would seem best to account for the data, alternative explanations might be entertained and will need to be tested. However, position biasing may not be applicable to lamination in this system. Even though many fibers were inserted into nonoptic layers of tectum and some grew for up to $1000 \mu \mathrm{m}$ through these layers, fibers showed a marked preference for the optic layers giving no indication of being able to form synapses in the nonoptic layers.

Suggestion for an integrated approach. There are two intellectual undercurrents that, in the author's opinion, have contributed to a certain lack of consensus in this field. One is the notion that each of the general hypotheses explaining the formation of orderly connection, in particular marker-mediated growth and positional factors, are alternative explanations, only one of which is correct. The other is that markers should be thought of only as determining highly specific sites of innervation and are incompatible with plasticity or mismatching between fibers and target. The present finding again calls into question other notions and suggests that markers are responsible for preferential growth as was originally proposed (Sperry, 1951) rather than rigidly determining the innervation pattern.

While markers predispose fibers toward particular growth paths and innervation sites, the particular expression of these growth preferences depends on other factors such as the initial starting position and the presence or absence of other fibers. If this view is correct, it becomes important to clearly define the role of preferential growth and to clarify what other factors may contribute to the pattern of innervation. By way of illustrating such an integrative approach, a working hypothesis called vector affinity is presented briefly. It is meant to explain only gross topography and not refined topography and ocular dominance columns (Constantine-Paton and Law, 1978; Meyer, 1979) which are probably mediated through an activity-dependent sorting of synapses (Meyer, 1982a, b, 1983).

The following is assumed: (1) Any given optic fiber is intrinsically capable of terminating at any tectal location within the optic layers. There is no recognition for or special compatibility with the correct tectal region. (2) The probability of a fiber terminating at any given tectal locus is proportional to the time its synaptogenic region, presumably its growth cone, is in contact with a given tectal neuron. (3) There exist distributed retinal and tectal markers possibly as a gradient as originally proposed (Sperry, 1963). These markers produce net direc- 
tional growth, a growth vector. (Net directional growth is meant to include the possibility of trial and error branching with selective resorption of errant branches.) The directionality of this growth is highest in foreign tectal regions and reduced or absent in the appropriate region. In other words growth directionality is progressively lost as a fiber enters its correct tectal region. (How localized the "correct" tectal region is remains to be clarified since in goldfish there is a progressive posterior shift in the projection as a consequence of asymmetrical retinal and tectal growth (Johns and Easter, 1978; Meyer, 1978b.) (4) The rate of growth (rate of increase in axoplasm and membrane) is a scalar (directionless) quantity and is independent of tectal locus. Scalar growth continues after fibers enter their correct tectal region to produce a local arborization, since each branch is equally correct in its direction of growth. Arborization increases contact time between individual fibers and tectal cells and promotes synapse formation as per assumption 2. (5) Rate of growth (scalar growth) of any given fiber is inversely proportional to the number of synapses made by that fiber. Growth largely stops when a characteristic number of synapses is formed. (6) If the density of fibers is sufficiently high, competition for limited postsynaptic sites will take place. Fibers with the highest scalar growth in a specific tectal region, i.e., fibers with lowest vectoral growth in the region, will be most competitive as per assumptions 2 and 4.

This hypothesis would have predicted the two main findings of the study: (1) it predicts that fibers which are introduced into the wrong part of tectum will grow toward their normal area of innervation; (2) it predicts that fibers will distribute themselves along their growth path when there is no competition from other retinal fibers. If the full complement of optic fibers were present and if fibers were allowed free choice of pathway such as following simple nerve crush, then a more orderly projection would be expected. The model serves to illustate that a number of processes often viewed as alternative explanations can just as easily be conceived to operate in a highly interdependent fashion. In fact some of the traditional distinctions become blurred. If as suggested markers determine pathway and pathway in turn determines the innervation pattern, then the distinction bctween marker-mediated growth (chemoaffinity) and pathway guidance is arbitrary and of questionable value.

\section{References}

Attardi, D. G., and R. W. Sperry (1963) Preferential selection of central pathways by regenerating optic fibers. Exp. Neurol. 7: 46-64.

Bunt, S. M. (1982) Retinotopic and temporal organization of the optic nerve and tracts in the adult goldfish. J. Comp. Neurol. 206: 209-226.

Constantine-Paton, M., and M. I. Law (1978) Eye-specific termination bonds in tecta of three-eyed frogs. Science 202 : 639-641.

Conway, K., K. Feiock, and R. K. Hunt (1980) Polyclones and patterns in growing Xenopus eye. Curr. Top. Dev. Biol. 15: $217-317$.

Cook, J. E. (1979) Interactions between optic fibres controlling the location of their terminals in the goldfish optic tectum. J. Embryol. Exp. Morphol. 52: 89-103.
Cowan, W. M., D. I. Gottlieb, A. E. Hendrickson, J. L. Price, and T. A. Woolsey (1972) The autoradiographic demonstration of axonal connections in the central nervous system. Brain Res. 37: 21-51.

Fraser, S. E., and R. K. Hunt (1980) Retinotectal specificity: Models and experiments in search of a mapping function. Annu. Rev. Neurosci. 3: 319-352.

Fujisawa, H. (1981) Retinotopic analysis of fiber pathways in the regenerating retinotectal system of the adult newt $C y n o p s$ pyrrhogaster. Brain Res. 206: 27-37.

Gaze, R. M., and M. J. Keating (1972) The visual system and "neuronal specificity." Nature 237: 375-378.

Gaze, R. M., and S. C. Sharma (1970) Axial differences in the reinnervation of the goldfish optic tectum by regenerating optic nerve fibers. Exp. Brain Res. 10: 171-181.

Goldstein, D. J., and M. A. Williams (1971) Quantitative autoradiography: An evaluation of visual grain counting, reflectance microscopy, gross absorbance measurements and flying-spot microdensitometry. J. Microsc. 94: 215-239.

Grafstein, B., and M. Murray (1969) Transport of protein in goldfish optic nerve during regeneration. Exp. Neurol. 25. 494-508.

Hope, R. A., B. J. Hammond, and R. M. Gaze (1976) The arrow model: Retinotectal specificty and map formation in the goldfish visual system. Proc. R. Soc. Lond. (Biol.) 194: 447466.

Horder, T. J. (1974) Changes of fibre pathways in the goldfish optic tract following regeneration. Brain Res. 72: 41-52.

Horder, T. J., and K. A. C. Martin (1978) Morphogenetics as an alternative to chemospecificity in the formation of nerve connections. In Cell-Cell Recognition, A. S. G. Curtis, ed., pp. 275-358, Cambridge University Press, Cambridge, England.

Hunt, R. K., and M. Jacobson (1974) Neuronal specificity revisited. Curr. Top. Dev. Biol. 8: 203-259.

Jacobson, N., and R. L. Levine (1975) Plasticity in the adult frog brain: Filling the visual scotoma after excision or translocation of parts of the optic tectum. Brain Res. 88: 339-345.

Johns, P. R., and S. S. Easter (1978) Growth of the adult goldfish eye. II. Increase in retinal cell number. J. Comp. Neurol. 176: 331-342.

Levine, R. L., and M. Jacobson (1975) Discontinuous mapping of retina onto tectum innervated by both eyes. Brain Res. 98: $172-176$.

Levine, R. L., and R. Y. S. Lo (1982) The miswired goldfish brain: Long-term persistence and transcience of retinal projections following tectal lobe removal. Brain Res. 242: 11-18.

Meyer, R. L. (1975) Tests for field regulation in the retinotectal system of goldfish. In Developmental Biology, Pattern Formation, Gene Regulation, D. McMahon and C. F. Fox, eds., pp. 257-275, W. I. Benjamin, Menlo Park, CA.

Meyer, R. L. (1977) Eye-in-water electrophysiological mapping of goldfish with and without tectal lesions. Exp. Neurol. 56: 23-41.

Meyer, R. L. (1978a) Deflection of selected optic fibers into a denervated tectum in goldfish. Brain Res. 155: 213-227.

Meyer, R. L. (1978b) Evidence from thymidine labelling for continuing growth of retina and tectum in juvenile goldfish. Exp. Neurol. 59: 99-111.

Meyer, R. L. (1979) "Extra" optic fibers exclude normal fibers from tectal regions in goldfish. J. Comp. Neurol. 183: 883902.

Meyer, R. L. (1980) Mapping the normal and regenerating retinotectal projection of goldfish with autoradiographic methods. J. Comp. Neurol. 189: 273-289.

Meyer, R. L. (1982a) Ordering of retinotectal connections: A multivariate operational analysis. Curr. Top. Dev. Biol. 17: 101-145.

Meyer, R. L. (1982b) Tetrodotoxin blocks the formation of 
ocular dominance columns in goldfïsh. Science 218: 589-591.

Meyer, R. L. (1983) Tetrodotoxin inhibits the formation of refined retinotopography in goldfish. Dev. Brain Res. 6: 293298.

Meyer, R. L., and R. W. Sperry (1976) Retinotectal specificity: Chemoaffinity theory. In Studies on the Development of Behavior and the Nervous System. Vol. 3: Neural and Behavioral Specificity, G. Gottlieb, ed., pp. 111-149, Academic Press, Inc., New York.

Murray, M. (1976) Regeneration of retinal axons into the goldfish optic tectum. J. Comp. Neurol. 168: 175-196.

Murray, M., and M. A. Edwards (1982) A quantitative study of the reinnervation of the goldfish optic tectum following optic nerve crush. J. Comp. Neurol. 209: 363-373.

Prestige, M. C., and D. J. Willshaw (1975) On a role for competition in the formation of patterned neural connections. Proc. R. Soc. Lond. [Biol.] 190: 77-98.

Rho, J. H., and R. K. Hunt (1980) Retinal projection to a surgically prepared "double-lateral" tectum in Xenopus: Electrophysiological studies. Dev. Biol. 80: 436-453.

Schmidt, J. T. (1978) Retinal fibers alter tectal positional markers during the expansion of the retinal projection in goldfish. J. Comp. Neurol. 177: 279-300.

Schmidt, J. T., C. M. Cicerone, and S. S. Easter (1978) Expansion of the half retinal projection to the tectum in goldfish: An electrophysiological and anatomical study. J. Comp. Neurol. 177: 257-278.

Sharma, S. C., and R. M. Gaze (1971) The retinotopic organi- zation of visual responses from tectal reimplants in adult goldfish. Arch. Ital. Biol. 109: 357-366.

Sharma, S. C., and Y. L. Tung (1979) Interactions between nasal and temporal hemiretinal fibers in adult goldfish tectum. Neuroscience 4: 113-119.

Singer, M., R. H. Nordlander, and M. Egar (1979) Axonal guidance during embryogenesis and regeneration in the spinal cord of the newt: The blueprint hypothesis of neuronal pathway patterning. J. Comp. Neurol. 15: 1-22.

Sperry, R. W. (1951) Mechanisms of neural maturation. In Handbook of Experimental Psychology, S. S. Stevens, ed., pp. 236-280, John Wiley \& Sons, Inc., New York.

Sperry, R. W. (1963) Chemoaffinity in the orderly growth of nerve fiber patterns and connections. Proc. Natl. Acad. Sci. U. S. A. 50: 703-710.

Strumer, C. (1981) Modified retinotectal projection in goldfish: A consequence of the position of retinal lesions. In LesionInduced Neuronal Plasticity in Sensorimotor Systems, $\mathrm{H}$. Flohr and W. Precht, eds., pp. 369-376, Springer-Verlag, Berlin.

Udin, S. B. (1978) Permanent disorganization of the regenerating optic tract in the frog. Exp. Neurol. 58: 455-470.

Vanegas, H., M. Laufer, and J. Amat (1974) The optic tectum of a perciform teleost. I. General configuration and cytoarchitecture. J. Comp. Neurol. 154: 43-60.

Yoon, M. G. (1973) Retention of the original topographic polarity by the $180^{\circ}$ rotated tectal reimplant in young adult goldfish: J. Physiol. (Lond.) 233: 575-588. 